\title{
Globalization and Wage Polarization*
}

\author{
Guido Cozzi ${ }^{\dagger}$ \\ Giammario Impullitti ${ }^{\ddagger}$ \\ (University of St. Gallen) \\ (University of Nottingham) \\ July 182015
}

\begin{abstract}
In the 1980s and 1990s, the US labour market experiences a remarkable polarization along with fast technological catch-up, as Europe and Japan improve their global innovation performance. Is foreign technological convergence an important source of wage polarization? To answer this question, we build a multi-country Schumpeterian growth model with heterogeneous workers, endogenous skill formation and occupational choice. We show that convergence produces polarization through business stealing and increasing competition in global innovation races. Quantitative analysis shows that these channels can be important sources of US polarization. Moreover, the model delivers predictions on the US wealth-income ratio consistent with empirical evidence.
\end{abstract}

*We thank the Editor, Philippe Aghion, and two anonymous referees for their comments. We would also like to thank Ufuk Akcigit, Tiago Cavalcanti, David Hemous and seminar participants at the Bank of Portugal, Cambridge, Durham, EUI Florence, IAE Barcelona, IIES Stocklhom, Konstanz, NBER SI, SED Warsaw, Rome Sapienza and Uppsala. A previous version of the paper circulated under the title "Globalization, Wage Polarization, and the Unstable Great Ratio."

†School of Economics and Political Science, University of St. Gallen. Email: guido.cozzi@unisg.ch.

${ }^{\ddagger}$ School of Economics, University of Nottingham. Email: Giammario.Impullitti@nottingham.ac.uk. 
Review of Economics and Statistics Just Accepted MS.

doi:10.1162/REST_a_00551

(C) by the President and Fellows of Harvard College and the Massachusetts Institute of Technology

JEL Classification: F16, J31, O33

Keywords: wage polarization, heterogeneous workers, wealth-income ratio, endogenous technical change, international technology competition, personal service sector.

\section{Introduction}

The US labour market has experienced a radical polarization of employment and wages in the last decades. In the 1980s and 1990s, both wages and employment shares at the tails of the skill distribution have grown steadily. Workers in the middle of the distribution instead have faced stagnant wages and shrinking employment share (Acemoglu and Autor, 2011). Recent empirical work has shown that also the wealth to income ratio has been increasing steadily since the mid-1970s in the US (Piketty and Zucman, 2014). Here, we make an explorative attempt to assess the role of globalization, in the form of fiercer foreign technological competition, in shaping these important developments of the US economy.

In the years of expanding labour market polarization, the US economy became increasingly globalized. The massive reduction in trade barriers and the diffusion of technologies across countries' borders allowed foreign firms, mostly from Japan and Europe, to challenge US technological leadership. The geography of technological leadership, measured as countries' share of innovation inputs and outputs, shows remarkable changes between the mid-1970s and the late 1980s. As the distribution of leadership moved from drastically skewed toward the US, to a more equal global playing field, clear convergence patterns can be observed in the share of patents, patent citations and R\&D spending. The share of foreign patents in the US Patent Office, was about one third in 1977 and grew to about one half ten years later. The US share of global industrial R\&D declined from about 50 percent in 1979 to 39 percent in 1995. Most of this technological catching-up was due to a massive acceleration in Japanese innovation activity, although some European countries, such as Germany and France, played a major role in some sectors (Impullitti, 2010, and Akcigit, Ates, and Impullitti, 2014). 
Review of Economics and Statistics Just Accepted MS.

doi:10.1162/REST_a_00551

(C) by the President and Fellows of Harvard College and the Massachusetts Institute of Technology

Did the acceleration of foreign technological competition in the 1980s contribute to the polarization of the US labour market? To answer this question we construct a quality ladder growth model (Aghion and Howitt, 1992, and Grossman and Helpman, 1991) with two asymmetric countries and heterogeneous workers. Firms compete for global market leadership investing in quality-improving innovation. Schumpeterian competition for innovation allows successful innovators to replace incumbents. The asymmetry between countries is represented by a technology gap in innovation: firms in the leading country have a better innovation technology in all sectors of the economy. There are three occupations: innovation, production, and services: innovation workers are employed in the production of new ideas to improve the quality of the goods. Blue collar, production workers, are employed in the manufacturing of goods. Service sector workers provide personal services that allow their employer to save working time. Workers have heterogeneous ability and can acquire working skills through education. Educational attainment allows workers to become skilled and work in innovation activities. Workers who do not acquire education can work as production workers or in service occupations.

In equilibrium, the following allocation of abilities to occupations is obtained: workers with high innate ability become skilled and hire service sector workers, those with intermediate ability work in production occupations and finally, those at the bottom of the ability distribution work in personal service occupations. Reductions in the technology gap has the following effects on the leading economy: First, as foreign firms start innovating more efficiently, they obtain quality leadership in more sectors, thereby stealing market shares from firms in the leading country and reducing the demand of production workers. This business-stealing effect reduces wages of production workers in the leading economy. Second, the reduction in the technology gap makes it harder for domestic firms to innovate in the global economy, thus pushing them to devote more labour resources to innovation. This global competition effect triggers an increase in the demand for skilled workers. Via these two channels, increasing foreign competition generates more polarization in the leading economy's labour market: the wage of skilled workers relative to that of production workers increases, thereby raising inequality at the top of the skill distribution. The wage of service sector workers relative to that of production workers increases, 
Review of Economics and Statistics Just Accepted MS.

doi:10.1162/REST_a_00551

(C) by the President and Fellows of Harvard College and the Massachusetts Institute of Technology

thus reducing inequality at the bottom of the distribution. The increase in the demand and wages of service sector workers is a by-product of rising inequality at the top of the distribution. As skilled labour time becomes more valuable, skilled workers demand more personal services in order to free time to devote to their highly remunerative job.

Another key prediction of our model is the positive link between foreign technological competition, innovation, and the wealth-income ratio. The business-stealing and the global competition effect of foreign technological catching up increase the value of innovation in the global economy. In our Schumpeterian economy, the value of innovation is determined by the value of the leading firm in each product line, and aggregate wealth consists in the sum of the market values of all leading firms. Hence, our model establishes a natural connection between international competition, innovation and the dynamics of the wealth-income ratio.

In an extended version of the model, we allow for a more general technology where skilled and unskilled workers are employed in production and innovation with different factor intensities, we introduce iceberg trade costs, and we specify the workers' ability distribution. We then calibrate this generalized model and use it to explore the link between the technology gap, labour market polarization and the wealth-income ratio quantitatively. In our two-country world, the US is the leading economy and the rest of the world represents the foreign country. The technology gap between countries is calibrated to reproduce the distribution of patents in the US Patent Office. A closure of the innovation technology gap reproduces a sizable part of the convergence in US and foreign patent shares shown in the data between 1980 and 2000, along with a non-negligible share of wage and jobs polarization: our model can replicate about $10 \%$ of the increase in inequality at the top of the distribution, $16 \%$ of the increase in the skill premium and about $18 \%$ of the decrease in inequality at the bottom observed between 1980 and 2000. Finally, the decline in the technology gap generates a striking increase in the US wealth-income ratio, reproducing about two thirds of the change documented by Piketty and Zucman (2014).

The recent empirical evidence on labour market polarization in the US has triggered a new line of research aimed at understanding those facts. Autor and Dorn (2013) present a 
Review of Economics and Statistics Just Accepted MS.

doi:10.1162/REST_a_00551

(C) by the President and Fellows of Harvard College and the Massachusetts Institute of Technology

simple "task-based" model with capital-skill complementarity formalizing the so-called "routinization" hypothesis. This hypothesis posits that technological change complements skilled tasks, replaces routine tasks, and is neutral to service occupations. Hence technology affects the wage structure through a postulated factor bias. We propose a complementary approach according to which polarization is driven by the factor intensity of innovation rather than the factor bias of technological progress. Moreover, Autor and Dorn treat technological progress and the supply of skills as exogenous 1 We complement their analysis by endogenizing both technological change and skill formation, as well as by exploring the key role of globalization.

In our economy, the increase in the demand and wages of service sector workers relative to other unskilled tasks comes from a general equilibrium market mechanism: foreign competition raises inequality at the top of the distribution, thereby inducing skilled workers to demand more personal services and devote more time to their highly paid jobs. This mechanism finds direct empirical support in Mazzolari and Ragusa (2013) who, using US city-level data, show that the increase in the top wages bill can explain about one-third of the growth of employment of non-college workers in low-skill personal services in the 1990s.

Finally, our paper is also related to the literature on globalization and wage inequality. A large body of work has studied the effects of trade liberalization on wage inequality across workers with different skills when technology is constant (e.g. Epifani and Gancia, 2008, Burstein and Vogel, 2010), or when technology is endogenous and interacts with trade in shaping the wage structure (e.g. Dinopoulos and Segerstrom, 1999, and Acemoglu, 2003). We depart from this literature along two main lines: first, while existing papers focus on economies with two skills and explain the evolution of the skilled-unskilled wage gap, the skill premium, we work in environments with a continuum of skills allocated to different occupations which allows us to study inequality in several parts of the wage distribution. Second, we move from a widely studied dimension of globalization, trade liberalization, to the less explored channel of cross-

${ }^{1}$ Hemous and Olsen (2014) embed the routinization hypothesis into a fully-fledged dynamic model of directed technical change and show that technological progress can generate phases of polarization and phases where inequality increases uniformly. 
Review of Economics and Statistics Just Accepted MS.

doi:10.1162/REST_a_00551

(C) by the President and Fellows of Harvard College and the Massachusetts Institute of Technology

country technological catch up. A small emerging literature has started to analyze the effects of foreign technological catching up on growth and welfare (e.g. Eaton and Kortum, 2007, Hsie and Ossa, 2011, Impullitti, 2010, Akcigit, Ates, and Impullitti, 2014). Our paper contributes to this line of research studying the effects of foreign catching up on the structure of wages, employment, and on the evolution of the wealth to income ratio. ${ }^{2}$

\section{Stylized facts}

In this section, we discuss some key facts providing the motivation for the paper as well as empirical support for the quantitative analysis.

Wage polarization. Since the early 1980s, the US has shown a remarkable increase in labor market polarization. Autor and Dorn (2013) document a non-monotonic change in employment and wages along the skill distribution. Working with Census IPUMS and American Community Survey data, they rank 318 occupations in all US nonfarm employment by skill level using the average wages of workers in each occupation. Their results show that employment changes in the period 1980-2005 have an inverted U-shaped pattern. Employment in the middle of the skill distribution declines substantially, while the tails show a steady and somewhat puzzling increase. Digging deeper into the occupational structure of these changes they document that most of the increase in employment and wages in the lower tail can be attributed to one group of occupations that they name service occupations. These are low-education occupations involving caring, assisting and entertaining other people, such as, cleaners, janitors, security guards, food service workers, gardeners, home health aides, hairdressers, beauticians, and recreation occupations. Table 1 below shows the employment dynamics for three groups of occupations. Skilled workers include the occupations at the top of the skill distribution. Unskilled workers outside service occupations comprises a low-educated occupational group including production and crafts jobs, operative and assembly occupations, transportation, construction, mechanical,

\footnotetext{
${ }^{2}$ Impullitti (2015), analyses the effects of foreign competition on the skill premium and on residual inequality in the presence of offshoring.
} 
Review of Economics and Statistics Just Accepted MS.

doi:10.1162/REST_a_00551

(C) by the President and Fellows of Harvard College and the Massachusetts Institute of Technology

mining, clerical and retails sales jobs. The third group includes the service occupations described above. The data show a strong increase in the employment share of skilled workers, which grew by $25 \%$ between 1980 and 2000. Similarly, the employment share of service occupations increased by about 17\% in the 1980-2000 period. On the other hand, the employment share of unskilled non-service occupations declined by about $16 \%$. 
Review of Economics and Statistics Just Accepted MS.

doi:10.1162/REST_a_00551

(C) by the President and Fellows of Harvard College and the Massachusetts Institute of Technology

Table 1: Employment Share by Major Occupation Groups: 1980-2000

\begin{tabular}{lcccc}
\hline \hline & Levels & & growth \\
& 1980 & 1990 & 2000 & $80-00$ \\
\hline Skilled workers & 31.55 & 38.16 & 39.61 & 0.25 \\
Manager/Prof/Tech/Finance/Public Safety & & & & \\
Unskill no-service & 58.52 & 51.31 & 48.77 & -0.16 \\
Production/Craft & 4.82 & 4.78 & 3.54 & -0.23 \\
Transp/Constr/Mech/Mining/Farm & 21.5 & 18.7 & 18 & -0.16 \\
Machine Operators/Assembly & & & & \\
Clerical/RetailSales & 9.94 & 7.30 & 5.70 & -0.42 \\
& & & & \\
Unskill service & 22.2 & 21.6 & 21.4 & -0.04 \\
& & & & \\
\hline \hline
\end{tabular}

Source: Autor and Dorn (2013) 
Review of Economics and Statistics Just Accepted MS.

doi:10.1162/REST_a_00551

(C) by the President and Fellows of Harvard College and the Massachusetts Institute of Technology

Table 2: Mean Real Hourly Wages by Major Occupation Groups: 1980-2000

\begin{tabular}{|c|c|c|c|c|}
\hline & \multicolumn{3}{|c|}{ Levels } & \multirow{2}{*}{$\begin{array}{l}\text { growth } \\
80-00 \\
\end{array}$} \\
\hline & 1980 & 1990 & 2000 & \\
\hline & \multicolumn{4}{|c|}{ Mean Log Hourly Wage (2004\$) } \\
\hline Skilled workers & 2.82 & 2.89 & 3.02 & 0.19 \\
\hline Unskill no-service & 2.58 & 2.58 & 2.62 & 0.04 \\
\hline Unskill service & 2.09 & 2.14 & 2.24 & 0.14 \\
\hline Skilll Premium & 1.37 & 1.47 & 1.60 & 0.17 \\
\hline Skill/Unskill(no serv) & 1.27 & 1.36 & 1.49 & 0.21 \\
\hline Unskill(no serv)/Serv & 1.62 & 1.55 & 1.46 & -0.16 \\
\hline
\end{tabular}

Source: Autor and Dorn (2013) 
Table 2 shows the levels and changes in wages for the three groups of occupations in the same period. We can see a substantial increase in wages of skilled workers and a smaller but non-negligible increase in service occupations' wages. The wages of unskilled workers in nonservice occupations instead exhibit virtually no change. Focusing on the relative changes across these groups, we can look at the dynamics of the gap between the top and the middle of the distribution and that between the middle and the bottom. The first gap is represented by the ratio of skilled over unskilled (non-service) wages, which shows a $21 \%$ increase up to 2000. The second gap is the ratio between the wages of unskilled workers outside of personal service occupations and those of service workers. This ratio declines by 16 percentage points up to 2000. We also compute a more standard measure of inequality, the skill premium, defined as the average wage of skilled workers over of the average wage of all unskilled workers, including service sectors workers $3^{3}$ In line with inequality at the top of the distribution, the skill premium shows a remarkable increase after 1980 .

The wealth to income ratio. Piketty and Zucman (2014) report that the wealth to income ratio in the US rose from slightly above $350 \%$ in 1980 to $450 \%$ in 2000 . The wealth of a nation is defined as the sum of domestic capital and net foreign assets. In the US, the foreign asset position in those years is negligible, hence the wealth to income ratio and domestic capital to income ratio coincide. For this reason, they use the terms wealth-income and capital-income ratio interchangeably. Capital in the data is the sum of agricultural land, housing, the value of financial assets net of liabilities and the value of net non-financial assets. Figure 2 shows the evolution of private wealth and its components in the period we are analyzing. As we can see, financial wealth is the driving force of the increasing wealth to income ratio, while housing wealth (net of mortgages) and non-financial assets, which include tangible capital, are fairly constant. 4

${ }^{3}$ The average unskilled wage is obtained using the employment shares of the unskilled (no service) and service occupation workers as weights.

${ }^{4}$ Non financial assets include produced tangible capital and non-produced tangible capital. Tangible assets is the typical economic measure of physical capital which includes all tangible 
Review of Economics and Statistics Just Accepted MS.

doi:10.1162/REST_a_00551

(C) by the President and Fellows of Harvard College and the Massachusetts Institute of Technology

fixed assets: buildings and structures, machinery and equipment, cultivated biological resources, weapon systems, etc. Non-produced tangibles includes natural resources such as land, oil, gas. 
Review of Economics and Statistics Just Accepted MS.

doi:10.1162/REST_a_00551

(C) by the President and Fellows of Harvard College and the Massachusetts Institute of Technology

Figure 1: Composition of Private Wealth, 1980-00, \% National Income

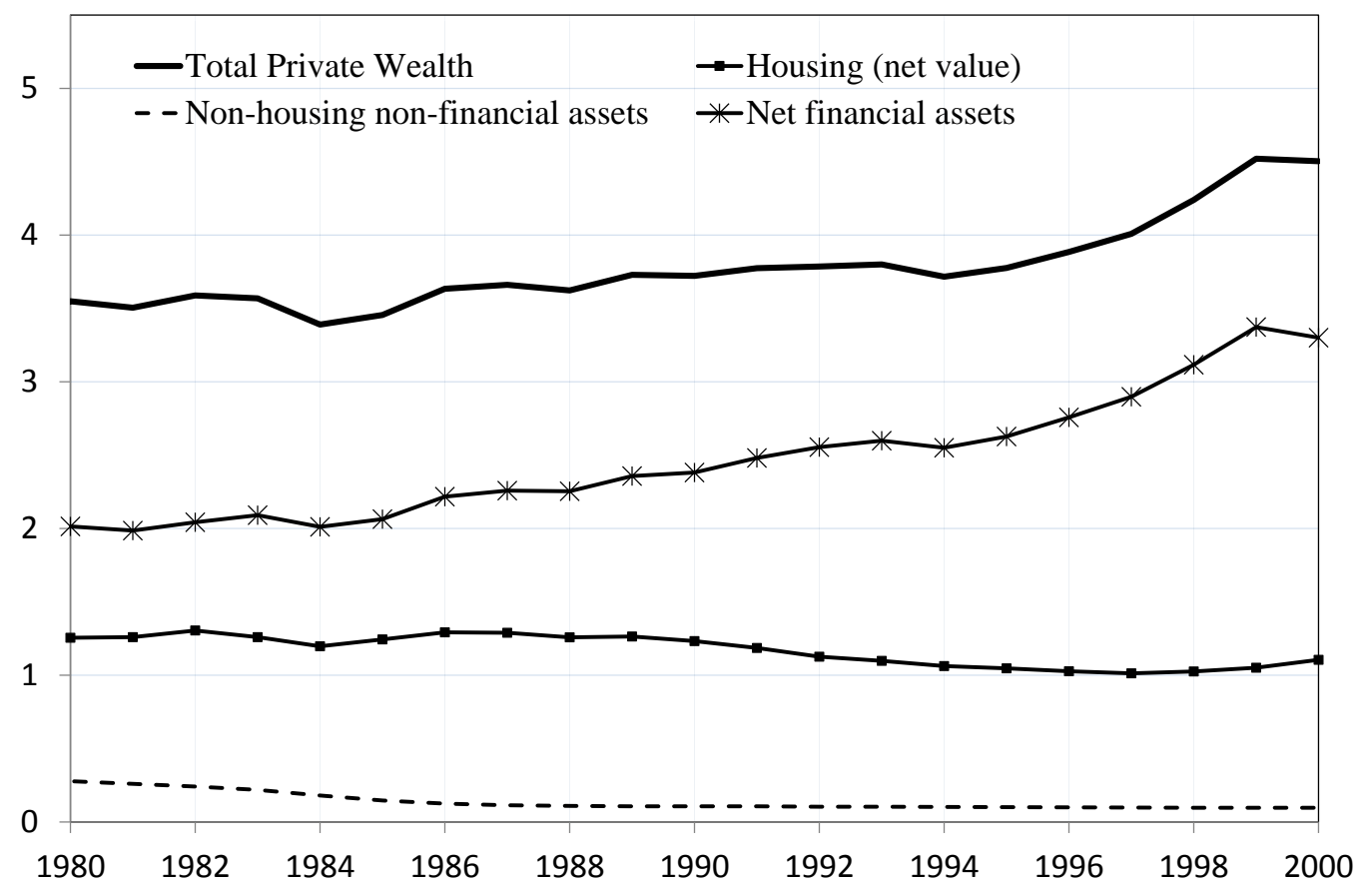

Source: Piketty and Zucman (2014). 
Review of Economics and Statistics Just Accepted MS.

doi:10.1162/REST_a_00551

(C) by the President and Fellows of Harvard College and the Massachusetts Institute of Technology

About two thirds of financial assets are accounted for by corporate wealth. In Figure 2, we report the two measures of corporate wealth constructed by Piketty and Zucman (2014). The first measure is the equity value, which is the market value of the firm, and the second is the net worth, which is the "book value" of the firm which comes from a perpetual inventory method-based estimates of tangible assets. The difference between the two measures is the residual corporate wealth, and their ratio is the well-known Tobin's Q. 
Review of Economics and Statistics Just Accepted MS.

doi:10.1162/REST_a_00551

(C) by the President and Fellows of Harvard College and the Massachusetts Institute of Technology

Figure 2: Corporate Wealth, 1980-00, \% National Income

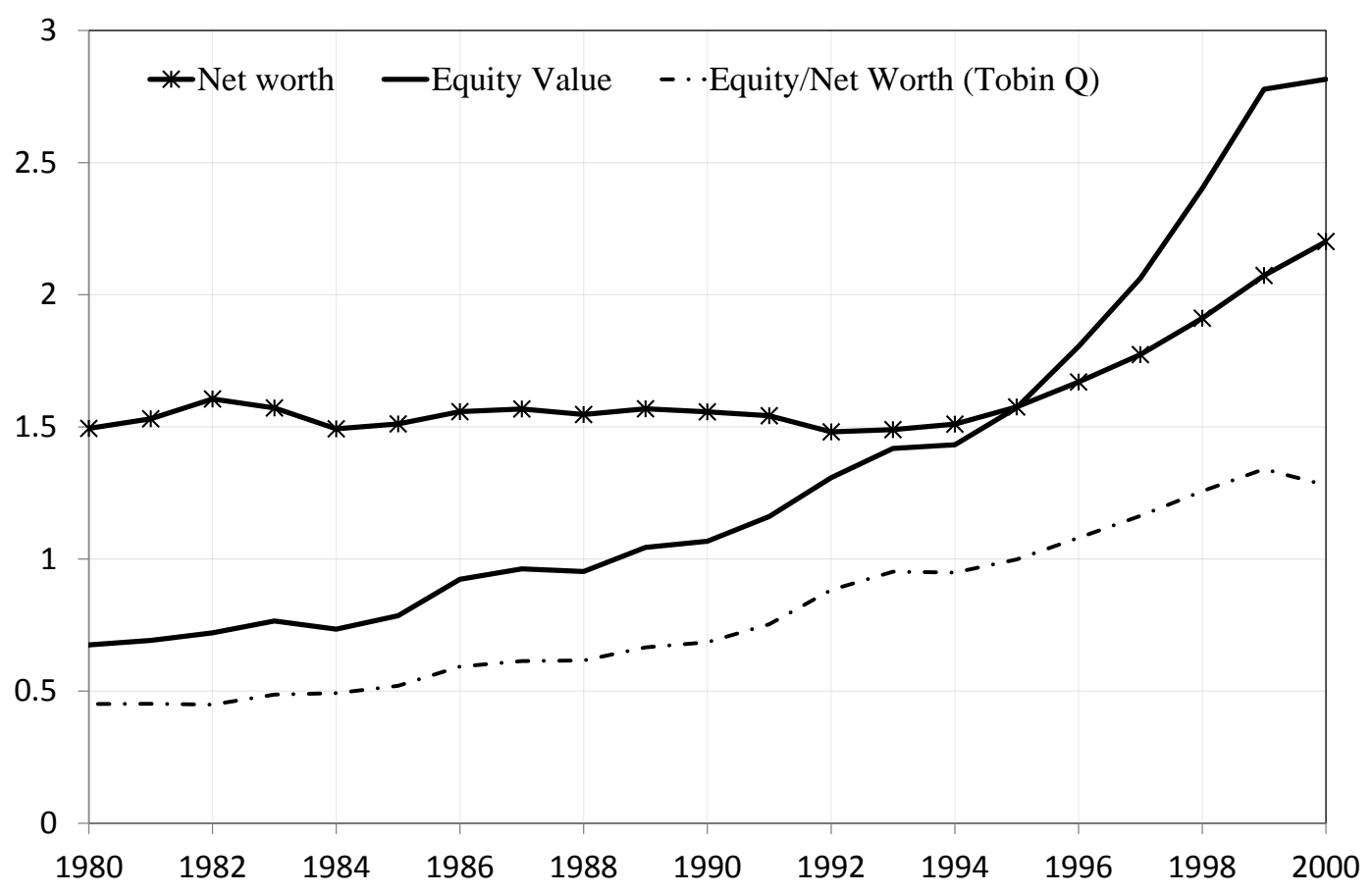

Source: Piketty and Zucman (2014). 
Review of Economics and Statistics Just Accepted MS.

doi:10.1162/REST_a_00551

(C) by the President and Fellows of Harvard College and the Massachusetts Institute of Technology

Both measures of corporate wealth exhibit a striking increase in the period of interest. The book value rises from $150 \%$ of income in 1980 to $220 \%$ in 2000 , while the equity value from $67 \%$ in 1980 skyrockets to $280 \%$ in 2000 .

International technological competition. During this period of increasing wage polarization and fast growing wealth-income ratio, the US experienced increasing foreign technological competition. The data show a global convergence pattern in several measures of innovation performance. The US, the undisputed technological leader in the post-World War II period, was progressively challenged by Japan and European countries in the late 1970s and 1980s. Figure 3, shows the stark convergence in patent shares in the US Patent office; in 1977 about two thirds of patents came from American firms, while ten years later only one half of patents had US origins. Most of the convergence takes place in the 1970s and 1980s, while the following years show no major changes. 
Review of Economics and Statistics Just Accepted MS.

doi:10.1162/REST_a_00551

(C) by the President and Fellows of Harvard College and the Massachusetts Institute of Technology

Figure 3: Share of US and Foreign Patents in US Patent Office

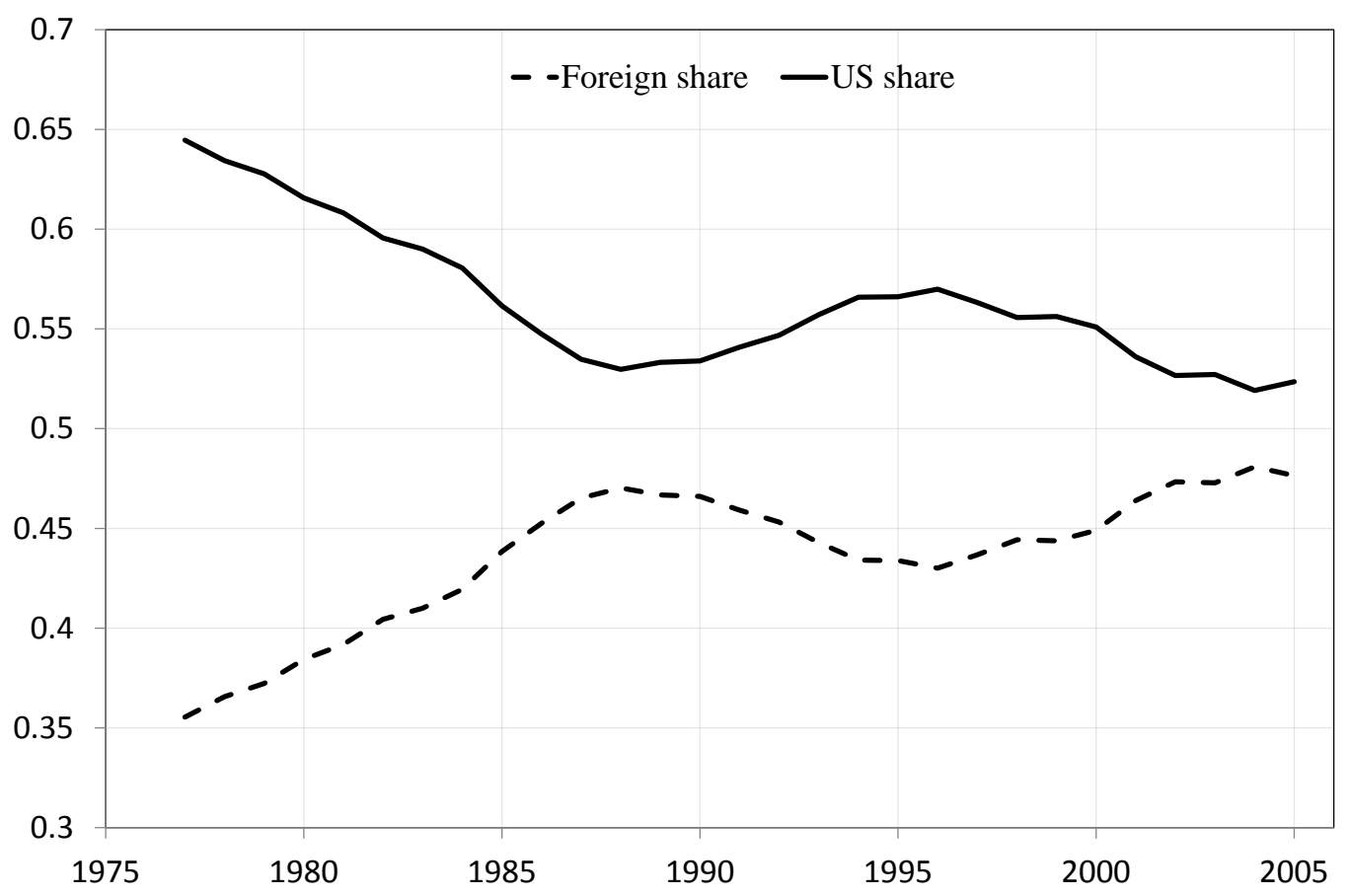

Source: United States Patent and Trademark Office. 
This convergence in patenting activity did not happen because of a slowdown in US patenting but it is due to a stark acceleration in foreign patents. The number of foreign patents grew by about $60 \%$ between 1977 and 1988, while US patents did not show any sensible change in those years. This increase is mainly driven by Japan, whose share rose from 9\% in 1977 to about $20 \%$ in 1988. Along these lines, Akcigit, Ates, and Impullitti (2014) show that a similar trend can be seen in patent citations. Disaggregating at the level of technology classes, they document a convergence trend in global patenting also at the micro/sectorial level. Together with convergence in innovation output (patents), recent research has also highlighted similar patterns for global innovation inputs. Impullitti (2010) documents a strong convergence in private R\&D spending between the US and a group of fast growing advanced economies in the 1970s and 1980s.

\section{The model}

In this section, we present the baseline model and use it to analyze the interaction between globalization, innovation and the occupation and wage structure.

\subsection{Households}

Consumption. The economy is populated by two regions with the same population and preferences. In both regions, households are heterogeneous in their abilities to acquire skills. At birth, members draw their ability $\theta \in[0,1]$ from a distribution $\Gamma(\theta)$. Households have identical preferences for a continuum of consumption goods $\omega \in[0,1]$, and each is endowed with a unit of labour or study time whose supply generates no disutility. Household of type $\theta$ is modelled as dynastic family that maximizes intertemporal utility

$$
U=\int_{0}^{\infty} N(0) e^{-(\rho-n) t} \ln u_{\theta}(t) d t
$$

where population is specified according to $N(t)=N(0) e^{n t}$, with initial population $N(0)$ normalized to 1 and a constant population growth rate $n$. The rate of time preference is $\rho$, with 
$\rho>n$. The utility per person is given by

$$
u_{\theta}(t) \equiv\left[\int_{0}^{1}\left(\sum_{j=0}^{j^{\max }(\omega, t)} \lambda^{j} d_{\theta}(j, \omega, t)\right)^{\frac{\eta-1}{\eta}} d \omega\right]^{\frac{\eta}{\eta-1}}
$$

where $d_{\theta}(j, \omega, t)$ is the per member quantity of good $\omega \in[0,1]$ of quality $j \in\{0,1,2, \ldots\}$ purchased by a household of ability $\theta$ at time $t \geq 0$. A new vintage of good $\omega$ yields a quality $\lambda$ times that of the previous vintage, with $\lambda>1$. Different versions of the same good $\omega$ are regarded by consumers as perfect substitutes after adjusting for their quality ratios, and $j^{\max }(\omega, t)$ denotes the maximum quality in which the good $\omega$ is available at time $t$. Parameter $\eta \in[1, \infty)$ is the elasticity of substitution across varieties, which allows for gross substitutability across varieties.

At each point in time, households choose the quantity purchased of each good $d_{\theta}(j, \omega, t)$ in order to maximize 22 subject to the per period expenditure constraint $\int_{0}^{1} d_{\theta}(j, \omega, t) p(j, \omega, t) d \omega=$ $c_{\theta}(t)$, where $c_{\theta}(t)$ is planned time $t$ consumption expenditure. Notice that the household will be purchasing in each line only the product with the lowest price per unit of quality. Hence, household's demand for each product is:

$$
d_{\theta}(j, \omega, t)=c_{\theta}(t) \frac{q(\omega, t) P(t)^{\eta-1}}{p(j, \omega, t)^{\eta}}
$$

where $q(\omega, t)=\lambda^{(\eta-1) j^{\max }(\omega, t)}$ represents the quality of good $\omega$ and $P(t)$ is a general price index, defined as:

$$
P(t)=\left[\int_{0}^{1} q(\omega, t) p\left(j^{\max }(\omega, t), \omega, t\right)^{1-\eta} d \omega\right]^{\frac{1}{1-\eta}}
$$

Notice that the quality of the demanded version of a variety, $q(\omega, t)$, positively affects its quantity, while negatively affecting the overall price index. Given the optimal allocation of expenditures across different product lines at a given moment $t$ in (3), households choose the intertemporal allocation of consumption maximizing (1) with respect to the intertemporal budget constraint $\dot{a_{\theta}}(t)=w_{\theta}(t)+(r(t)-n) a_{\theta}(t)-c_{y}(t)$, where asset market clearing implies that per capita assets are equal to the sum of firm values $a(t)=\int_{0}^{1} v(\omega, t) d \omega$. This problem 
yields

$$
\frac{\dot{c_{\theta}}(t)}{c_{\theta}(t)}=r(t)-\rho
$$

the standard Euler equation for consumption.

Supply of skills and personal services. Individuals are finitely-lived members of infinitely-lived households, being continuously born at rate $\beta_{n}$ and dying at rate $\delta$, with $\beta_{n}-$ $\delta=n>0 ; V>0$ denotes the exogenous duration of their liff5. They choose to acquire education and become skilled, if at all, at the beginning of their lives; and for the duration of their schooling period, denoted $T_{H}<V$, the individual cannot work. We assume agents have heterogeneous innate abilities drawn from a cumulative distribution function $\Gamma(\theta)$.

In country $K=D$ (domestic), $F$ (foreign) an individual with ability $\theta$ decides to acquire education if the expected wage income is larger than that of working as unskilled, that is:

$$
\int_{t}^{t+V} e^{-\int_{t}^{s} r(\tau) d \tau} \theta w_{L}^{K}(s) d s \leq \int_{t+T_{H}}^{t+V} e^{-\int_{t}^{s} r(\tau) d \tau} \max \left(\theta-\gamma_{H}, 0\right) w_{H}^{K}(s) d s,
$$

where $w_{L}^{K}$ and $w_{H}^{k}$ are the wage per unit of abilities of the unskilled and skilled workers, respectively. Parameter $0<\gamma_{H}<1$ establishes a threshold ability requirement so that an agent with ability $\theta>\gamma_{H}$ is able to accumulate $\theta-\gamma_{H}$ units of skills after schooling, while a person with ability below $\gamma_{H}$ gains no skills from education. Parameter $\gamma_{H}$ can be interpreted as a fixed cost of education in terms of the skilled wage. We will here focus on steady-state analysis, in which all variables grow at constant rate and $w_{L}, w_{H}$, and $c_{\theta}$ are all constant. From the Euler equation (4) we obtain $r(t)=\rho$ at all dates. Equation (5) yields the cutoff ability level $\theta_{0}^{K}$ above which agents acquire education:

$$
\frac{w_{H}^{K}}{w_{L}^{K}}=\sigma_{1}\left(\frac{\theta_{0}^{K}}{\theta_{0}^{K}-\gamma_{H}}\right)
$$

with $\sigma_{1} \equiv\left[\left(e^{\rho V}-1\right) /\left(e^{\rho\left(V-T_{H}\right)}-1\right)\right]>1$. Notice that, since $0<\gamma_{H}<1$, we have that an

${ }^{5}$ It is easy to show that the above parameters cannot be chosen independently, but that they must satisfy $\delta=n /\left(e^{n V}-1\right)$ and $\beta=n e^{n V} /\left(e^{n V}-1\right)$ in order for the number of births at time $t$ to match the number of deaths at $t+V$. 
increase in the relative skilled wage $w_{H}^{K} / w_{L}^{K}$ reduces the ability cutoff to acquire education $\theta_{0}^{K}$.

Each unskilled individual can work either in production occupations or as a personal service worker. Personal services allow people to spend less time on house chores, baby-sitting, transportation, and other activities, which would otherwise detract time from other kinds of activities, such as production and innovation occupations. Since in this model individuals do not have a desire for leisure, we can assume that each hour saved thanks to service workers will be used to work more. We will also posit that there is an upper bound, normalized to 1 , of the extra work made possible by personal services $6^{6}$ Moreover, each unit time of personal service provides its employer, who must be a different person, $1-\epsilon$ extra time for work, with $0<\epsilon<1$. This implies that in equilibrium, unskilled workers of same or lower ability levels will not demand services, because it would $\operatorname{cost} w_{L}^{K}$ to obtain an extra labour time which pays $w_{L}^{K}(1-\epsilon)$.

A high skilled worker of generic ability $\theta$ finds it profitable to buy personal services from an unskilled worker of ability $\theta^{\prime}$, if at the cost of $\theta^{\prime} w_{L}^{K}$ they can obtain an additional wage income $w_{H}^{K}(1-\epsilon) \theta \geq \theta^{\prime} w_{L}^{K}$. The lowest possible $\theta$ at which hiring a personal service is worthwhile in country $K$, denoted $\theta_{H S}^{K}$, and the higher possible $\theta^{\prime}$ supplied by the unskilled, denoted $\theta_{L S}^{K}$, must equalize the service cost and employer's economic benefit, that is:

$$
\theta_{L S}^{K} w_{L}^{K}=w_{H}^{K}(1-\epsilon)\left[\theta_{H S}^{K}-\gamma_{H}\right]
$$

The mass of service workers must be equal to the mass of skilled workers employing them,

$$
\Gamma\left(\theta_{L S}^{K}\right)=1-\Gamma\left(\theta_{H S}^{K}\right)
$$

Plugging equation (8) into (7) and solving for $\theta_{L S}^{K}$ gives

$$
\theta_{L S}^{K}\left(\theta_{H S}^{K}\right) \equiv \Gamma^{-1}\left(1-\Gamma\left(\theta_{H S}^{K}\right)\right)=\frac{w_{H}^{K}}{w_{L}^{K}}(1-\epsilon)\left[\theta_{H S}^{K}-\gamma_{H}\right]
$$

\footnotetext{
${ }^{6}$ There is no restriction in this normalization, this upper bound can be easily generalized.
} 
which since $\Gamma^{-1}($.$) is monotonically increasing, gives \theta_{H S}^{K}$ as a decreasing function of the relative skilled wage, and therefore $\theta_{L S}^{K}$ as an increasing function of the relative skilled wage. Intuitively, a higher relative remuneration of skilled occupations increases the demand for service occupations. Hence, invoking (6), we can write, $d \theta_{H S}^{K} / d \theta_{0}^{K}>0$ and $d \theta_{L S}^{K} / d \theta_{0}^{K}<0$.

The fraction of the population opting out of education determines the per capita supply

of unskilled labour $L^{K} \equiv \widetilde{\theta}_{L}^{K} \Gamma\left(\theta_{0}^{K}\right)$, where $\widetilde{\theta}_{L}^{K}=\int_{0}^{\theta_{0}^{K}} \theta d \Gamma(\theta) / \Gamma\left(\theta_{0}^{K}\right)$ is the average ability of a generic unskilled worker. Notice that $d L^{K} / d \theta_{0}^{K}=\theta_{0}^{K}>0$, the supply of unskilled workers, is increasing in $\theta_{0}^{K}$. Intuitively, a higher relative skilled wage reduces the cutoff ability to acquire education $\theta_{0}^{K}$, thereby reducing the share of unskilled workers. A fraction $1-\Gamma\left(\theta_{0}^{K}\right)$ of the population decides to attain education and the skilled workforce is represented by the subset of these agents that as of date $t$ have completed their schooling period, that is individuals born between $t-V$ and $t-T_{r}$. The per capita supply of skilled labour in efficiency units at time $t$ is then

$$
H^{K}=\widetilde{\theta}_{H}^{K}\left[1-\Gamma\left(\theta_{0}^{K}\right)\right] \int_{t-V}^{t-T r} \beta_{n} N(0) e^{n s} d s=\widetilde{\theta}_{H}^{K}\left[1-\Gamma\left(\theta_{0}^{K}\right)\right] \phi,
$$

with $0<\phi \equiv\left(e^{n\left(V-T_{r}\right)}-1\right) /\left(e^{n V}-1\right)<1$ and

$$
\widetilde{\theta}_{H}^{K}=(2-\epsilon) \int_{\theta_{H S}^{K}}^{1}\left(\theta-\gamma_{H}\right) \frac{d \Gamma(\theta)}{1-\Gamma\left(\theta_{0}^{K}\right)}+\int_{\theta_{0}^{K}}^{\theta_{H S}^{K}}\left(\theta-\gamma_{H}\right) \frac{d \Gamma(\theta)}{1-\Gamma\left(\theta_{0}^{K}\right)}
$$

is the average ability of educated workers, which takes into account that above the cutoff $\theta_{H S}^{K}$ workers get and extra $1-\epsilon$ working time from hiring service workers. Using (11) we derive

$$
d H^{K} / d \theta_{0}^{K}=-\left[(1-\epsilon) \frac{d \theta_{H S}^{K}}{d \theta_{0}^{K}}+1\right]\left(\theta_{0}^{K}-\gamma_{H}\right) \Gamma^{\prime}\left(\theta_{0}^{K}\right) \phi<0,
$$

hence the supply of skills is decreasing in $\theta_{0}^{K}$.

\subsection{Production}

In each country, firms can hire unskilled workers to produce consumption good, $\omega \in[0,1]$,under a constant returns to scale technology with one worker producing one unit of product. The 
Review of Economics and Statistics Just Accepted MS.

doi:10.1162/REST_a_00551

(C) by the President and Fellows of Harvard College and the Massachusetts Institute of Technology

unskilled wage rate is $w_{L}^{K}$ and we set $w_{L}^{F}=1$, so that the unskilled foreign wage is the numeraire of this economy. Assuming instantaneous price competition, Bertrand equilibrium implies that in each industry only the product with the highest quality is produced. Quality leaders in each sector are challenged by followers that employ skilled workers to discover the next top-quality product. In this model, as typical of quality ladder frameworks, a patent expires as soon as the next top-quality product is invented. Successful innovation yields global market leadership, which is protected by a perfectly enforceable patent law.

We assume that the technologies to produce goods one quality ladder below the top are obsolete and diffuse freely. This assumption allows foreign successful innovators to become global market leaders.7 We allow for international trade in goods, but we do not consider multinational companies in this model. In addition, while allowing for perfect patent protection, we rule out an international market for patent royalties. Therefore, in our model, only domestic firms can produce and export the goods patented in the country. Finally, we do not consider international trade in assets.

As will become clearer in the next sections, as a consequence of the technology gap between the two countries, country $D$ has global market leadership in a wider range of sectors, which drives up the demand for its manufacturing labour. For this reason, in all our equilibria the unskilled wage in country $D$ will be higher than that of country $F$, that is $w_{L}^{D}>w_{L}^{F}$. Since both domestic and foreign followers operate with the same technology, and foreign unskilled labour is cheaper, domestic followers are not an effective competitive threat. Moreover, we assume that the quality jump $\lambda$ is not high enough that each top-quality producer firm can maximize

\footnotetext{
${ }^{7}$ Without this assumption if a leader experiences successive innovations, followers will be pushed out of the market permanently. The assumption of immediate diffusion of the old production technology is discussed in Glass (1997) and widely used both in North-North models of trade and growth (e.g. Dinopoulos and Segerstrom, 1999), and in North-South models (Glass, 1997).
} 
profits unconstrained in both markets 8 . Thus the price of a top-quality good in a sector $\omega$ is

$$
p^{K}\left(j^{\max }(\omega, t), \omega, t\right)=\lambda w_{L}^{F}(t)=\lambda>1 .
$$

Notice that this implies that $w_{L}^{D} \leq \lambda w_{L}^{F}$, because otherwise country $D$ firms would lose all markets and unskilled job:9 This "narrow gap" case (Grossman and Helpman, 1991) allows for equilibrium product-cycle trade (Vernon, 1966) with global market leadership shifting from domestic to foreign firms as the latter innovate and viceversa. Although the foreign region has a cost advantage in production, equilibrium guarantees that the wage gap is not so large that a foreign follower can price a domestic leader out of the market without innovating.

From demand (3), we conclude that the demand for each product $\omega$ is

$$
N(t)\left(c^{D}(t)+c^{F}(t)\right) \frac{q(\omega, t) P(t)^{\eta-1}}{p(j, \omega, t)^{\eta}}=d(\omega, t),
$$

where $c^{K}(t)=\int_{0}^{1} c_{\theta}^{K}(t) d \theta$ is average per capita expenditure. Notice that under the pricing condition 12 the price index becomes, $P(t)^{\eta-1}=\lambda^{\eta-1} / Q(t)$, where $Q(t)=\int_{0}^{1} q(\omega, t) d \omega$ is the average quality in the economy. Therefore, using (13) and dropping time indexes for notational simplicity, we can write:

$$
d(\omega)=\frac{N\left(c^{D}+c^{F}\right) q(\omega)}{\lambda Q}, \text { for } \omega \in[0,1]
$$

Since supply and demand of goods are equal in equilibrium, the stream of monopoly profits accruing to domestic quality leaders is $\pi_{n}^{D}(\omega)=N\left(c^{D}+c^{F}\right) q(\omega)\left(\lambda-w_{L}^{D}\right) / \lambda Q$, and the profit of the foreign leader is $\pi^{F}(\omega)=N\left(c^{D}+c^{F}\right) q(\omega)(\lambda-1) / \lambda Q$.

${ }^{8}$ Cases in which this does not hold can be easily handled, with no qualitative change in the results.

${ }^{9}$ This includes those in the service sector, because innovation would stop - due to lack of expected profits in manufacturing, and skilled workers would lose their jobs as well. 


\subsection{Global innovation races and the value of a firm}

In each industry, firms employ skilled workers to discover the next top-quality version of their products. The arrival rate of innovation in industry $\omega$ at time $t$ is $I(\omega, t)$, which is the sum of the Poisson arrival rate of innovation produced by all firms targeting product $\omega$. The innovation technology available to a firm $i$ in region $K$ for innovation in sector $\omega$ is

$$
I_{i}^{K}(\omega, t)=\frac{A^{K} h_{i}^{K}(\omega, t)\left(\frac{H^{K}(\omega, t)}{X(\omega, t)}\right)^{-\alpha}}{X(\omega, t)},
$$

where $h_{i}^{K}(\omega, t)$ is labor input in innovation by firm $i$, in industry $\omega$, and $X(\omega, t)>0$ measures the degree of complexity of innovation, $\alpha$ is a positive congestion parameter, and $H^{K}(\omega, t)=$ $\sum_{i} h_{i}^{K}(\omega, t)$ and $I^{K}(\omega, t)=\sum_{i} I_{i}^{K}(\omega, t)$ are the total skilled labour and the total innovation rates in sector $\omega$ respectively. This technology implies that each firm's instantaneous probability of success is a decreasing function of the total domestic labour resources devoted to innovation in an industry. A possible interpretation of this property is that when firms increase innovation inputs in a sector, the probability of duplicative innovation effort also increases, thereby reducing the probability that any single firm discovers the next vintage of goods. Therefore, the sector-specific negative externality in innovation technology produces decreasing returns to innovation at the industry level. Moreover, (15) implies that this negative externality is also region-specific 10

Notice that equation 15 implies $I^{K}(\omega, t)=A^{K}\left(H^{K}(\omega, t) / X(\omega, t)\right)^{1-\alpha}$. The complexity index $X(\omega, t)$ is introduced to avoid the counterfactual prediction of the first generation innovation-driven growth models that the size of a region affects its steady-state growth (Jones,

\footnotetext{
${ }^{10}$ There is strong empirical evidence on the nonlinearity of the relationship between innovative activity of a country (measured using patent data) and its R\&D investment. Working with a large sample of US firm-level data, Hall et al. (1986) find an elasticity of patents to R\&D of 0.5. The evidence surveyed in Kortum (1993) suggests point estimates for the patent/R\&D elasticity in the range 0.1 - 0.6. More recently, Blundell et al. (2002) find a long-run elasticity of 0.5 .
} 
1995). We eliminate the strong scale effect by assuming

$$
X(\omega, t)=\frac{q(\omega, t)}{Q(t)^{\phi_{1}}}
$$

with $0<\phi_{1}<1$. Therefore, the more advanced the good relative to the average quality the more difficult a further innovation. Moreover, even for an average quality good (i.e. if there exists an $\omega$ such that $q(\omega, t)=Q(t))$, the higher the average quality itself the more difficult innovation (in this case $X(\omega, t)=Q_{t}^{1-\phi_{1}}$ ), which incorporates Jones (1995) increasing complexity argument to rule out the strong scale effect. Equation (16) implies that, log-differentiating the difficulty index between quality jumps in the sector, its evolution obeys $\dot{X}(\omega, t) / X(\omega, t)=-\phi_{1} \dot{Q}(t) / Q(t)$.

Each innovating firm chooses the labour resources devoted to innovation $h_{i}^{K}$ in order to maximize its expected discounted profits. Free entry into innovation races drives profits to zero, yielding

$$
v^{K}(\omega, t)\left(\frac{I^{K}(\omega, t)}{A^{K}}\right)^{\frac{-\alpha}{1-\alpha}} \frac{A^{K}}{X(\omega, t)}=w_{H}^{K}(t)
$$

where $v^{K}(\omega, t)$ is the value of a firm in sector $\omega$ and country $K$. This condition states that the cost of one unit of skilled labour employed in innovation $w_{H}^{K}$ must be equal to its benefits, represented by the marginal product of labor in innovation $A^{K}\left(L^{K}(\omega, t) / X(\omega, t)\right)^{-\alpha} / X(\omega, t)$ times the prize for a successful innovation $v^{K}(\omega, t)$. Notice that, despite the leaders and followers having the same production and innovation technology, the free entry condition implies that we can compute the equilibrium focusing only on the followers' innovation 11

Efficient financial markets channel savings into innovative firms that issue a security paying the new monopoly stock market value if they win the race and zero otherwise. Since there is a continuum of industries, and simultaneous and independent innovation races, consumers can perfectly diversify away risk: the expected rate of return of a stock issued by a firm is equal to the riskless rate of return $r(t)$. It is easy to show that this leads to the following stock market

${ }^{11}$ This is the celebrated Arrow effect (see Cozzi, 2007), introduced by Aghion and Howitt (1992) into Schumpeterian growth theory. 
value of a firm:

$$
v^{K}(\omega, t)=\frac{\pi^{K}(\omega, t)}{r(t)+I(\omega, t)-\dot{v}^{K}(\omega, t) / v^{K}(\omega, t)},
$$

where $I(\omega, t)$ denotes the worldwide Poisson arrival rate of an innovation that will destroy the monopolist's profits in industry $\omega$. This is the Schumpeterian rate of creative destruction, which implies that the expected value of a patent is decreasing in the total innovation of the industry. Substituting for the value of the firm from $(18)$ into $(17)$ and using $(15)$ to express the amount of skilled workers in terms of the innovation rate we obtain the following conditions

$\frac{\pi^{K}(\omega, t)}{r(t)+I(\omega, t)-\dot{v}^{K}(\omega, t) / v^{K}(\omega, t)}\left(\frac{I^{K}(\omega, t)}{A^{K}}\right)^{\frac{-\alpha}{1-\alpha}} \frac{A^{K}}{X(\omega, t)}=w_{H}^{K}(t)$, for $\omega \in[0,1]$ and $K=D, F$.

These conditions, together with the Euler equation, summarizes the utility maximizing household choice of consumption, savings, and education, and the profit maximizing choice of production and innovation. Innovation arrival rates determine the evolution of the average quality of goods in the economy $Q_{t}$. Finally, in all industries, firms from both regions compete in innovation. Hence global innovation in each sector is $I(\omega, t)=I^{D}(\omega, t)+I^{F}(\omega, t)$, where $I^{D}(\omega, t)$ and $I^{F}(\omega, t)$ are domestic and foreign innovation.

Assumption 1 (Technology Gap). $A^{D}>A^{F}$.

We introduce a gap between the two countries in terms of the innovation technology parameter $A$. Since goods $\omega \in[0,1]$ are symmetric (same technologies, both in production and innovation, and enter the utility function symmetrically), the only source of structural asymmetry between the two countries is the difference between their innovation productivity. Since there is no sectorial heterogeneity in this economy, we can write, $I^{D}(\omega, t)=I^{D}(t)$ and $I^{F}(\omega, t)=I^{F}(t)$ for all $\omega$. In a steady state, the per industry probabilities of innovation per unit of time will be constant over time, which allows us to drop time indexes and write $I^{D}$ and $I^{F}$. Differentiating $Q$ with respect to time, it is straightforward to prove that:

$$
g=\frac{\dot{Q}}{Q}=\left(\lambda^{\eta-1}-1\right)\left(I^{D}+I^{F}\right)
$$


The growth rate of aggregate quality is proportional to the global arrival rate of innovation.

\subsection{Labour markets}

The production technology specified above implies that the demand for unskilled workers is equal to the total production of goods in each national economy plus the total demand for personal services. The unskilled labour market clearing condition is

$$
\left[\Gamma\left(\theta_{0}^{K}\right)-\left(1-\Gamma\left(\theta_{H S}^{K}\right)\right)\right] \widetilde{\theta}_{M}^{K}=\frac{\left(c^{D}+c^{F}\right)}{\lambda} q^{K},
$$

where $\widetilde{\theta}_{M}^{K}=\int_{\theta_{L S}^{K}}^{\theta_{0}^{K}} \theta^{K} d \Gamma(\theta) /\left(\Gamma\left(\theta_{0}^{K}\right)-\Gamma\left(\theta_{L S}^{K}\right)\right)$ is the average ability of unskilled workers employed in production. The left-hand side is the supply of unskilled workers in manufacturing in efficiency units. The right-hand side is the demand for unskilled workers. We define $q^{K}=Q^{K} / Q$, as the share of sectors with country $K^{\prime} s$ leadership, where $Q^{K}=\int_{B^{K}} q(\omega) d \omega$ is the average quality of the sectors in which country $K$ has global leadership $\left(B^{K}\right.$ is the measure of these sectors), and $q^{D}+q^{F}=1$ by construction ${ }^{12}$

The market clearing condition for skilled workers is

$$
\widetilde{\theta}_{H}^{K}\left(1-\Gamma\left(\theta_{0}^{K}\right) \phi=\left(\frac{I^{K}}{A^{K}}\right)^{1 /(1-\alpha)} \int_{0}^{1} \frac{X(\omega)}{N} d \omega=\left(\frac{I^{K}}{A^{K}}\right)^{1 /(1-\alpha)} x\right.
$$

where we define $x=Q^{1-\phi} / N=\int_{0}^{1} X(\omega) d \omega / N$, which is the aggregate difficulty index of innovation normalized by population. The left-hand side is the domestic supply of skilled labour (per capita) from (10), and the right-hand side is the domestic demand for skilled workers obtained after integrating equations 15 and 16 .

${ }^{12}$ At any point in time $B^{D} \cup B^{F}=[0,1]$; that is, each sector is either monopolized by a country $D$ firm or by a country $F$ firm. The measure of such sets is $q^{D}$, respectively $q^{F}$, with $q^{D}+q^{F}=1$. Notice that each $B^{K}$ changes over time as firms of different countries alternate their market leadership, but in the steady state its measure is constant. Moreover, $\dot{q}^{D}=q^{D} I^{D}-\left(1-q^{D}\right) I^{F}$, and $\dot{q}^{D}=0$ if and only if $q^{D}=I^{D} /\left(I^{D}+I^{F}\right)$. 
Wage Inequality. Since our main aim is to analyze the link between the technology gap and wage inequality, we need to specify the measures of inequality we want to focus on. The education choice and demand for service sector workers partition the worker/ability space as follows. Skilled workers are those whose abilities lie in $\left[\theta_{H S}^{K}, 1\right]$, who hire unskilled workers to perform personal services and therefore have extra time and income, and those, with ability in $\left[\theta_{0}^{K}, \theta_{H S}^{K}\right)$, who do not hire unskilled workers for performing personal services. The unskilled workers with ability in $\left(\theta_{L S}^{K}, \theta_{0}^{K}\right]$ work in the manufacturing sector, while those in $\left[0, \theta_{L S}^{K}\right]$ work in services. Hence, the average wage of skilled workers is the skilled wage per unit of skills $w_{H}^{D}$ times the average skill level of educated workers, $\tilde{w}_{H}^{D}=w_{H}^{D} \widetilde{\theta}_{H}^{D}$. Similarly, the average wage of the unskilled workers employed in production and the average wage of the service sector workers are

$$
\tilde{w}_{L}^{D}=w_{L}^{D} \widetilde{\theta}_{M}^{D}=w_{L}^{D} \int_{\theta_{L S}^{D}}^{\theta_{0}^{D}} \theta \frac{d \Gamma(\theta)}{\Gamma\left(\theta_{0}^{D}\right)-\Gamma\left(\theta_{L S}^{D}\right)}, \quad \tilde{w}_{S}^{D}=w_{L}^{D} \widetilde{\theta}_{S}^{D}=w_{L}^{D} \int_{0}^{\theta_{L S}^{D}} \theta \frac{d \Gamma(\theta)}{\Gamma\left(\theta_{0}^{D}\right)-\Gamma\left(\theta_{L S}^{D}\right)}
$$

respectively. We will mainly focus on two wage gaps: the skilled/unskilled (production) workers gap and the unskilled (production)/service workers gap, $\omega_{H}=\tilde{w}_{H}^{D} / \tilde{w}_{L}^{D}$ and $\omega_{S}=\tilde{w}_{S}^{D} / \tilde{w}_{L}^{D}$, both depending on the relative wage and on the relative average ability of workers.

\section{Steady-State Equilibrium}

A balanced growth path for this economy is an equilibrium in which per capita consumption $c^{K}$, innovation $I^{K}$, the share of industries with a domestic leader $q^{D}$, wages $w_{H}^{K}$ and $w_{L}^{K}$, and the ability cutoffs $\theta_{H S}^{K}$ and $\theta_{0}^{K}$ are constant, while the average quality of goods $Q$ grows at a constant rate. Since wages and sectorial innovation probabilities are constant in steady state, the free entry condition 17 and 16 imply that $\dot{v}^{K}(\omega) / v^{K}(\omega)=\dot{X}(\omega) / X(\omega)=-\phi_{1} \dot{Q} / Q$, for $K=D, F$ and for all $\omega \in[0,1]$. Since skill thresholds $\theta_{0}^{D}$ and $\theta_{0}^{F}$ are constant, from (22) also $Q^{1-\phi_{1}} / N$ has to be constant, which implies that $\dot{Q} / Q=n /\left(1-\phi_{1}\right)$ and therefore 
Review of Economics and Statistics Just Accepted MS.

doi:10.1162/REST_a_00551

(C) by the President and Fellows of Harvard College and the Massachusetts Institute of Technology

$\dot{X}(\omega) / X(\omega)=n \phi_{1} /\left(1-\phi_{1}\right)$. As a consequence, 20 implies that

$$
I^{D}+I^{F}=\frac{n}{\left(1-\phi_{1}\right)\left(\lambda^{\eta-1}-1\right)}
$$

Equation (24) dictates a long-term restriction on innovation rates based on the relative quality index and the sector sizes, thereby generalizing the "semi-endogenous growth" restrictions highlighted by Jones (1995). Quite interestingly, (24) shows that our version of increasing complexity allows some degree of endogeneity in the composition of innovation rates across sectors and countries. Per capita expenditure is constant in steady state, thus the Euler equation (4) yields $r=\rho$.

In steady state, the free entry conditions in innovation (19) take the following general form:

$$
\begin{aligned}
& \frac{\left(c^{D}+c^{F}\right)\left(\lambda-w_{L}^{D}\right)}{\left(\rho+I^{D}+I^{F}+\frac{n \phi_{1}}{1-\phi_{1}}\right) \lambda} A^{D}\left(\frac{1}{x}\right)\left(\frac{I^{D}}{A^{D}}\right)^{\frac{-\alpha}{1-\alpha}}=w_{H}^{D}, \\
& \frac{\left(c^{D}+c^{F}\right)(\lambda-1)}{\left(\rho+I^{D}+I^{F}+\frac{n \phi_{1}}{1-\phi_{1}}\right) \lambda} A^{F}\left(\frac{1}{x}\right)\left(\frac{I^{F}}{A^{F}}\right)^{\frac{-\alpha}{1-\alpha}}=w_{H}^{F},
\end{aligned}
$$

where we have the expressions for profits specified above. Moreover, the share of industries with country $K$ leadership is,

$$
q^{K}=\frac{Q^{K}}{Q}=\frac{I^{K}}{I^{D}+I^{F}} .
$$

To close the model we need to specify the national budget constraints. Consumption expenditure plus savings in each country equates national income, which is the value of the labour income (wages of unskilled and skilled workers) plus firm profits:

$$
\begin{aligned}
& c^{D}+w_{H}^{D} H^{D}=Y^{D}=\left[\frac{c^{D}+c^{F}}{\lambda} w_{L}^{D}+\frac{c^{D}+c^{F}}{\lambda}\left(\lambda-w_{L}^{D}\right)\right] q^{D}+w_{H}^{D} H^{D}, \\
& c^{F}+w_{H}^{F} H^{F}=Y^{S}=\left[\frac{c^{D}+c^{F}}{\lambda}+\frac{\left(c^{D}+c^{F}\right)}{\lambda}(\lambda-1)\right]\left(1-q^{D}\right)+w_{H}^{F} H^{F},
\end{aligned}
$$

where, since saving is equal to innovation spending, it appears both as an expenditure and as income (of the skilled workers). Moreover, to avoid double counting, we net out the wage 
of personal service workers, because they are paid by their employers (the skilled workers) in order to earn additional skilled wages. Using trade balance $c^{F} q^{D}=c^{D} q^{F}$ and simplifying the expressions above we can write national saving as

$$
\begin{aligned}
& S^{D}=Y^{D}-c^{D}=c^{F} q^{D}-c^{D} q^{F}+w_{H}^{D} H^{D}=w_{H}^{D} H^{D}, \\
& S^{F}=Y^{F}-c^{F}=c^{D} q^{F}-c^{F} q^{D}+w_{H}^{F} H^{F}=w_{H}^{F} H^{F} .
\end{aligned}
$$

Moreover, equations (28) and (29) are not independent, and they lead to

$$
\frac{c^{D}}{c^{F}}=\frac{q^{D}}{1-q^{D}} .
$$

The steady state equilibrium system is characterized by 13 unknowns $c^{D}, c^{F}, I^{D}, I^{F}, w_{L}^{D}, w_{H}^{D}$, $w_{H}^{F}, \theta_{0}^{D}, \theta_{0}^{F}, \theta_{H S}^{D}, \theta_{H S}^{F}, q^{D}, x$, and 13 equations (6), (9), 21), 22), 24), 25), 26), 27), and (32). Below we analyze its key properties.

\section{Analytical Results}

The goal of this section is to characterize some key equilibrium properties of the model. All proofs of propositions can be found in the online Appendix 13 We start with the following:

Proposition 1 In the steady state equilibrium, which always exists and is unique, country $D$ has leadership in a larger share of sectors $\left(q^{D}>q^{F}\right)$ and higher unskilled wages $\left(w_{L}^{D}>1\right)$ than country F.

The higher productivity of innovation, $A^{D}>A^{F}$, renders the domestic country more innovative $\left(I^{D}>I^{F}\right)$, and its firms obtain market leadership in a larger range of sectors $\left(q^{D}>q^{F}\right)$, which sustains a high demand for production workers and guarantees them higher wages than in the rest of the world $\left(w_{L}^{D}>1\right)$. The next proposition derives some comparative statics

${ }^{13}$ The online appendix can be found on the Review's web site, and on https://sites.google.com/site/gimpullitti/research-1. 
results with respect to a technological catch up by country $F$, modelled as an increases in $A^{F}$ given $A^{D}$.

Proposition 2 A reduction in the innovation technology gap $A^{D} / A^{F}$ produces the following effects:

i. The domestic unskilled wage $w_{L}^{D}$ decreases, the relative skilled wage $w_{H}^{D} / w_{L}^{D}$ increases along with the fraction of the population acquiring education (lower $\theta_{0}^{D}$ ).

ii. The fraction of sectors monopolized by domestic firms $q^{D}$ decreases.

iii. The fraction of the domestic labour force employed in personal services $\theta_{L S}^{D}$ increases and the fraction of labour force employed in production decreases.

$i v$. It is harder to innovate successfully in the global economy: the innovation difficulty index, $x$, increases.

$v$. Foreign skill and wage structure does not experience any change.

The effect of foreign technological competition on the skill and wage structure of the domestic country works through two different channels: the international business-stealing channel and the global competition channel. In providing the key economic intuitions, we focus on the link between changes in the technology gap and changes in the relative wage of skilled workers. As shown in section 3.1, the relative wage $w_{H}^{D} / w_{L}^{D}$ is the key variable that determines the whole wage and skill structure.

International business stealing. A reduction in the technology gap increases the relative innovation intensity $I^{F} / I^{D}$, thereby reducing the share of sectors with domestic leadership $q^{D}$. This is the business-stealing effect, typical of Schumpeterian models, in an open economy environment with two innovating asymmetric countries. As foreign innovation technology improves, foreign firms obtain global leadership in more sectors; as a consequence, production shifts away from the home market, thereby leading to lower labour demand and lower wages for unskilled production workers. Hence, a reduction in $w_{L}^{D}$ directly leads to higher relative skilled wage. Moreover, a reduction of unskilled wages increases domestic firm profits, thereby 
Review of Economics and Statistics Just Accepted MS.

doi:10.1162/REST_a_00551

(C) by the President and Fellows of Harvard College and the Massachusetts Institute of Technology

triggering an increase in the incentive to innovate and in the demand for skilled workers which further increases the relative skilled wage ${ }^{14}$

Global competition effect. Better foreign innovation technology generates an increase in the demand for skilled workers in the domestic country through its effect on the difficulty of innovation. As foreign innovation becomes relatively more productive, the relative innovation intensity $I^{F} / I^{D}$ increases. Due to the technology gap, country $D$ innovates more than $F$, and since innovation technology (15) has decreasing returns at the country level, an increase in $I^{F} / I^{D}$ raises global innovation efficiency leading to higher innovation and growth. In our semi-endogenous Schumpeterian growth model, steady-state quality growth is pinned down by population growth: combining (24) and (20) we obtain the steady-state growth rate,

$$
g=\frac{\dot{Q}}{Q}=\frac{n}{1-\phi_{1}} .
$$

The growth-enhancing effect of a lower international technology gap can then only be temporary, and fades away in the long run due to the increase in the innovation difficulty index. Equilibrium condition (24) implies that in steady state, domestic innovation $I^{D}$ decreases to exactly offset the increase in foreign innovation ${ }^{15}$ The skilled labour market clearing condition $(22)$ tells us then that, due to the increase in innovation difficulty, the domestic country is forced to devote more labour resources to innovation, and this triggers an increase in skilled wages ${ }^{16}$ We name this the global competition effect: stronger foreign competition for innovation makes it harder

\footnotetext{
${ }^{14}$ Recall that the markup for country $\mathrm{D}$ firms is $\left(\lambda / w_{L}^{D}-1\right) / \lambda$.

${ }^{15}$ Recall that our numeraire is the foreign unskilled wage, hence a reduction in $I^{D}$ must be interpreted as a decline in domestic innovation rate measured in terms of foreign unskilled wages.

${ }^{16}$ The skilled labour market clearing condition 22 can be written as $H\left(\theta_{0}^{D}\right)=$ $\left(I^{D} / A^{D}\right)^{1 /(1-\alpha)} x$, where $H\left(\theta_{0}^{D}\right)$ is the supply of skilled workers. A reduction in $A^{D} / A^{F}$ reduces $\theta_{0}^{D}$, thereby increasing $H\left(\theta_{0}^{D}\right)$ - since $d H\left(\theta_{0}^{D}\right) / d \theta_{0}^{D}<0$. For the market to clear, the increase in the supply of skilled workers must be matched by an equivalent increase in the demand.
} 
for domestic firms to innovate in the global economy, thus forcing them to devote more (skilled) labour to innovation.

Finally, because of the increase in the relative skilled wage $w_{H}^{D} / w_{L}^{D}$, skilled workers' time becomes more valuable, thus increasing the demand for service sector workers. The higher demand, in turns, attracts more unskilled workers into service occupations, thereby increasing the ability cutoff $\theta_{L S}^{D}$. Since more people acquire education and become skilled ( $\theta_{0}^{D}$ is lower) and more unskilled workers choose to be employed in service occupations ( $\theta_{L S}^{D}$ is higher), the share of unskilled workers in production shrinks.

As shown in the appendix, the equilibrium ability cutoff to acquire education for country $F$ can be obtained in closed form as a function of parameters, $\theta_{0}^{F} \equiv \bar{\theta}_{0}^{F}\left(n, \rho, \lambda, \eta, \phi_{1}, \phi, \sigma\right)$, and is independent on innovation efficiency parameters $A^{D}$ and $A^{F}$. Since $\theta_{0}^{F}$ is the key variable to determine the wage structure, if changes in the relative innovation efficiency do not affect this cutoff, labor market polarization remains unchanged. To interpret this result, recall that in this economy the competitive fringe pinning down the equilibrium pricing of firms is represented by the foreign country unit cost of production, the unskilled wage $w_{L}^{F}$, which is our numeraire. As discussed above, a reduction in the technology gap $A^{D} / A^{F}$ reduces the unskilled wage in country $D$, increases the profits of its firms, boosting innovation and the demand for skilled labor. In country $F$ this mechanism does not operate: since the competitive fringe is foreign unit cost, the markup of foreign firms is $(\lambda-1) / \lambda$, which implies that their profits are not affected by the reduction in the technology gap. As a consequence, the business-stealing effect does not lead to any change in the demand for skills, leaving the wage structure unaltered. In the extended model that we use for quantitative analysis, we show that in the presence of trade costs there exists a parameterization allowing the unit cost of both countries to potentially represent the competitive fringe. Under this parameterization the neutrality result discussed here breaks down, and changes in the technology gap affect polarization in both countries. Finally, notice that the global competition effect on the wage structure is not operative either: the increase in the difficulty index, which could potentially increase the demand for skills, is offset by the increase in the innovation efficiency $A^{F}$. 
In order to keep the analysis tractable and derive the final set of properties of our model, we now assume that abilities are distributed uniformly. This assumption allows us to move from predicting the effects of changes in the technology gap on the relative wages per units of skills, to predicting the effects on average wages at the top, the middle, and the bottom of the skill distribution.

Proposition 3 Under a uniform distribution of abilities, $\Gamma\left(\theta_{0}^{K}\right)=\theta_{0}^{K}$, a reduction in the innovation technology gap $A^{D} / A^{F}$ widens wage polarization in the domestic country:

i. The wage of average skilled workers relative to that of average unskilled production workers, $\tilde{w}_{H}^{D} / \tilde{w}_{L}^{D}$, increases.

ii. The average wage of service sector workers relative to that of unskilled production workers, $\tilde{w}_{S}^{D} / \tilde{w}_{L}^{D}$, increases.

As shown in Proposition 2, a reduction in the innovation technology gap increases the relative wage of skilled workers $w_{H}^{D} / w_{L}^{F}$. This effect produces changes in the average ability of skilled and unskilled workers that can potentially offset its impact on the average skilled/unskilled wage ratio $\tilde{w}_{H}^{D} / \tilde{w}_{L}^{D}$. On the one hand, as more people acquire education (lower $\theta_{0}^{D}$ ), the average quality of skilled workers $\widetilde{\theta}_{H}^{D}$ declines. On the other hand, a lower $\theta_{0}^{D}$ reduces the quality of unskilled workers employed in production while a higher $\theta_{L S}^{D}$ has the opposite effect. The relative strength of these forces determines the changes in the average quality of workers $\widetilde{\theta}_{H}^{D} / \widetilde{\theta}_{L}^{D}$. The result above shows that, under uniform ability distribution, the overall effect of a reduction in the technology gap on wage inequality in the upper tail of the skill distribution is positive.

Changes in the wage of service relative to production workers, $\tilde{w}_{S}^{D} / \tilde{w}_{L}^{D}$, are pinned down by the effects on the average quality of workers in these different occupations, as the wage per unit of skills is the same for all unskilled workers. The increase in the cutoff, $\theta_{L S}^{D}$, following the decline in the technology gap, increases the average quality of service workers, $\widetilde{\theta}_{S}^{D}$, but has an ambiguous effect on the average quality of production workers, as we saw above. With uniform ability distribution, the overall effect of lower technology gap on the relative service sector wage is positive. Hence, we can conclude that fiercer foreign technological competition brought about 
by a reduction in the innovation technology gap increases wage polarization, benefiting skilled workers and damaging workers in the middle of the skill distribution more than those at the bottom.

\subsection{Globalization and the wealth-income ratio: a Schumpeterian view}

Besides the predictions on the evolution of personal wage inequality, which tracks wage difference across individuals, our theory has implications for a different dimension of inequality, the wealth to income ratio. The data reported in Figure 1 show that the increase in the wealth to income ratio in the last decades is essentially due to the rise of financial assets, with housing and non-financial assets being substantially constant. More than two thirds of financial assets are represented by equities, the market value of corporations. Since the stock market value of firms is the core engine of growth in the Schumpeterian framework, our model is a good candidate to interpret the observed changes in the wealth-income ratio by linking them to the dynamics of international technological competition.

In our model, country $D$ 's aggregate wealth, denoted $W^{D}$, coincides with the stock market value of all the profit-generating firms in the economy, $W^{D}=\tilde{v}^{D} q^{D}$ where $\tilde{v}^{D}$ is the market value of a generic monopolistic firm ${ }^{17}$ As in the classical Schumpeterian theory (Aghion and Howitt, 1992), the innovation free-entry condition 19 equates the expected value of a new patent to the unit cost of innovation, here represented by the wage of a skilled labour unit. If we multiply both sides by the share of skilled workers in the economy $H^{D}$ and use 22 , the left hand side becomes the aggregate value of the flow of new patents and the right side the flow of savings in the economy, as shown in $(30), \tilde{v}^{D} I^{D}=w_{H}^{D} H^{D}$. Since by (24) and (33) $I^{D}=q^{D} g \bar{\lambda}$,

${ }^{17}$ The value of a generic monopolistic quality leader is

$$
\tilde{v}^{D} \equiv \frac{\left(c^{D}+c^{F}\right)\left(\lambda-w_{L}^{D}\right)}{\left(\rho+\frac{n}{\left(1-\phi_{1}\right)\left(\lambda^{\eta-1}-1\right)}+\frac{n \phi_{1}}{1-\phi_{1}}\right) \lambda} .
$$


we can write

$$
\underbrace{\tilde{v}^{D} q^{D}}_{\text {Wealth }} g \bar{\lambda}=\underbrace{w_{H}^{D} H^{D}}_{\text {Savings }}
$$

where $\bar{\lambda}=\left(\lambda^{\eta-1}-1\right)^{-1}$ and $g$ given by 33 are constant. The budget constraint 30 implies that savings are $S^{D}=w_{H}^{D} H^{D}$, and expressing aggregate savings $S^{D}$ as the product of the 'endogenous' marginal propensity to save multiplied by GDP, $S^{D}=s^{D} Y^{D}$, transforms 34 into:

$$
\tilde{\beta}^{D} \equiv \frac{W^{D}}{Y^{D}}=\frac{s^{D}}{g \bar{\lambda}} .
$$

This allows us to obtain the following result:

Proposition 4 A reduction in the innovation technology gap $A^{D} / A^{F}$ raises country $D$ 's wealth to national income ratio $\tilde{\beta}^{D}$.

The economic intuition is the following. Since in our semi-endogenous growth model the long-run growth rate is constant, the wealth to income ratio increases only if saving increases. As aggregate saving equals total investment in innovation, and the incentive to innovate is dictated by the market value of firms, the corporate wealth to income ratio is strictly increasing in innovation. Faster innovation in our economy has only transitional effects on growth which lead to persistently higher levels of saving and of the wealth-income ratio. Since in our model a reduction in the technology gap increases the demand for skilled workers and innovation spending in the leading country, it will also boosts the wealth to income ratio along with wage polarization.

We can conclude that, our model captures the salient stylized facts of the US labour market reported in Tables 1 and 2 and Figure 2, together with the evolution of the distribution of global patents shown in Figure 3.

\section{Quantitative analysis}

In order to take the model to the data we generalize it along two dimensions. First, we remove the assumption that skilled workers are used only in innovation and unskilled only in production. 
Secondly, we assume away free trade introducing trade barriers in the form of iceberg costs. We then calibrate the parameters of the model to match some key statistics of the data discussed in section 2, compute the numerical solution using the calibrated parameters and explore the effects of our dimension of globalization on wage polarization and the wealth-income ratio.

Generalizations. We generalize the technology of our economy allowing skilled and unskilled workers to be employed in both production and innovation. The production technology is defined by the unit cost function,

$$
Z^{K}\left(w_{L}^{K}, w_{H}^{K}\right)=\left(1 / z^{K}\right)\left(w_{L}^{K}\right)^{\beta}\left(w_{H}^{K}\right)^{1-\beta}, \text { for } K=D, F
$$

We assume that the unit production cost in country $F$ is the numeraire, that is $Z^{F}\left(w_{L}^{F}, w_{H}^{F}\right) \equiv 1$. The innovation technology is described by the unit cost function

$$
F^{K}\left(w_{L}^{K}, w_{H}^{K} ; A^{K}\right) X(\omega)=\left(1 / A^{K}\right) X(\omega)\left(w_{L}^{K}\right)^{\varphi}\left(w_{H}^{K}\right)^{1-\varphi}, K=D, F,
$$

where the difficulty index $X(\omega)=q(\omega) / Q^{\phi}$ is the same as in the benchmark model. As in the previous sections the technology gap is captured assuming $A^{D}>A^{F}$. The countryspecific production technology parameter $z^{K}$ is introduced for generality, and will not play any particular role besides that of contributing to the numerical fit of the model in the calibration.

Assumption 2. (Factor Intensity): $F_{H}^{K} / F_{L}^{K}>Z_{H}^{K} / Z_{L}^{K}$ : innovation is the skill intensive activity. With the Cobb-Douglas technologies above, the factor bias of innovation is pinned down by assuming $\beta>\varphi$ 18

This assumption implies less extreme factor intensity compared to the baseline model. As we will show, qualitatively it does not change the basic mechanisms: an increase in the incentive to

${ }^{18}$ This assumption guarantees a strictly concave transformation curve between the production of goods and innovation probabilities. Any parameter configuration wih $\beta \neq \varphi$ would avoid a linear transformation curve. The upside is that we do not need the congestion externality parameter $\alpha$ anymore, which can be set equal to zero at no loss. 
innovate will still increase the relative demand for skilled workers, and a reduction in a country's share of leadership will still reduce the relative demand for unskilled workers. Quantitatively, factor intensity parameters $\beta$ and $\varphi$ will be important to determine the size of these changes.

We also introduce trade barriers in the form of iceberg costs. Firms need to ship $\tau>1$ units of goods in order to sell one unit abroad. In the presence of trade costs, the "narrow gap" assumption becomes $\tau Z^{D}\left(w_{L}^{D}, w_{H}^{D}\right) / \lambda<Z^{F}\left(w_{L}^{F}, w_{H}^{F}\right)<Z^{D}\left(w_{L}^{D}, w_{H}^{D}\right)$. As in the basic model, this allows quality leaders in country $D$ to overcome a higher production cost by supplying a higher quality good. Trade costs complicate the optimal pricing of firms compared to the basic model. The optimal price choice of country $F$ firms selling their product domestically (that is, in country $F$ market) $p_{d}^{F}$, and the optimal pricing of country $D^{\prime} s$ exporting firms (that is, selling in country $F$ market) $p_{x}^{D}$ leads to the same limit pricing,

$$
p_{d}^{F}=\lambda Z^{F}\left(w_{L}^{F}, w_{H}^{F}\right)=\lambda=\lambda Z^{F}\left(w_{L}^{F}, w_{H}^{F}\right)=p_{x}^{D} .
$$

In fact, in both cases, the limit price is anchored to the quality jump, $\lambda$, times the unit cost of the world competitive fringe, which is country $F^{\prime} s$ production cost $Z^{F}=1$. Slightly more complex is the optimal strategy of firms selling in country $D$. In case $Z^{D}\left(w_{L}^{D}, w_{H}^{D}\right)>\tau$, the relevant competitive fringe would still be country $F$ firms able to enter with the previous version of the good. Then the optimal price choice of country $D$ firms selling their product domestically (that is, in country $D$ market) $p_{d}^{D}$ and the price choice of country $F$ exporting firms (that is, selling in country $D$ market) $p_{x}^{F}$ yield the same limit pricing,

$$
p_{d}^{D}=\tau \lambda Z^{F}\left(w_{L}^{F}, w_{H}^{F}\right)=\tau \lambda=\tau \lambda Z^{F}\left(w_{L}^{F}, w_{H}^{F}\right)=p_{x}^{F} .
$$

If instead $Z^{D}\left(w_{L}^{D}, w_{H}^{D}\right)<\tau$, the relevant competitive fringe in country $D$ market would be country $D$ firms able to enter with the previous version of the good. Consequently, the optimal price choice of country $D$ firms selling their product domestically and of country $F$ exporting firms leads to the same limit pricing, $p_{d}^{D}=\lambda Z^{D}\left(w_{L}^{D}, w_{H}^{D}\right)=p_{x}^{F}$. Finally, the two pricing strategies coincide in the case $Z^{D}\left(w_{L}^{D}, w_{H}^{D}\right)=\tau$. 
To stay close to the baseline model, in which only country $F$ firms effectively limit-price country $D$ firms, we add the assumption that firms in country $D$ have to pay a small fixed $\operatorname{cost} \varepsilon_{c}>0$ when they are competing with a quality leader of their own country. That is, the quality leader of country $D$ can create an additional cost (however small) to the domestic competitive fringe. For example, this could consist of small IPRs and legal barriers, distribution network and advertisement frictions, etc. We assume that this extra cost is entirely rebated to the consumer: 19 . Since firms operate under instantaneous price competition, each topquality producer country $D$ firm can then maximize its profits effectively being constrained only by threat of the foreign competitive fringe, not only if $Z^{D}\left(w_{L}^{D}, w_{H}^{D}\right) \geq \tau$ but also if $Z^{D}\left(w_{L}^{D}, w_{H}^{D}\right)<\tau$. ${ }^{20}$ Once we account for the different technologies and pricing strategies shown here, the rest of the model follows the same structure as the baseline framework. The detailed derivation can be found in the appendix.

Calibration. We assume that abilities are drawn from the cumulative distribution function $\Gamma(\theta)=\theta^{\varepsilon}$. This is a fairly general distribution function in $[0,1]$ : when $\varepsilon=1$, the ability is distributed uniformly in the population, when $0<\varepsilon<1$ the ability distribution is skewed towards low-ability workers, and for $\varepsilon>1$ the ability distribution is log concave. In the quantitative analysis, we explore the effects of the reduction of the international technology gap on inequality in the period 1980 to 2000 . The calibration period is one year. We have 17 parameters to calibrate: $\eta, \rho, n, \lambda, V, T_{H}, \epsilon, \varepsilon, \gamma_{H}, A^{D}, A^{F}, z^{D}, z^{F}, \phi_{1}, \varphi, \beta$, and $\tau$.

${ }^{19}$ This is just an innoquous simplification useful to eliminate $\varepsilon_{c}$ from all the equations. Otherwise we would have to keep track of this overhead cost of manufacturing, with no qualitative change in the results. Notice that since $\varepsilon_{c}$ can be arbitrarily small, it would not alter the calibration either, besides arbitrarily small rounding approximations.

${ }^{20}$ This assumption is not needed in the calibration, because parameters are still valid without the fixed costs. In fact, around the calibrated parameters $Z^{D}\left(w_{L}^{D}, w_{H}^{D}\right)>\tau$ holds anyway - even with $\varepsilon_{c}=0$. However, simulating the economy away enough from the calibrated parameters could at some point yield $Z^{D}\left(w_{L}^{D}, w_{H}^{D}\right)<\tau$, with consequent potential modification of the competitive environment of the industries. 
Nine parameters $n, \lambda, V, T_{H}, \gamma_{H}, \phi_{1}, \tau, \eta, \rho$, have close counterparts in the economy so that their calibration is straightforward. We set $\lambda$ to 1.3 , to match an average markup over the marginal cost of 30 per cent. Since the estimates of average sectorial mark-ups usually are in the interval $(0.1,0.4)$ (Basu 1996), we take a value within this range. We choose $n$ to match a population growth rate of 1.14 percent (Bureau of labour Statistics, 1999), the total schooling time $T_{H}=4$ to match the average years of college in the US, and the total working life $V=52$ to match a life expectancy at birth for cohorts turning 18 year old in 1979 of 70 years (National Vital Report Statistics, 2010) ${ }^{21}$ Autor and Dorn (2013) show that the labour share of the set of occupations that we classified as skilled is lower than 40 percent in the period of interest. We follow this evidence by choosing a threshold $\gamma_{H}=0.60$ to bound the share of skilled workers in our economy below 40 percent of the workforce. The current empirical literature provides a wide range of estimates for the elasticity of substitution between domestic and foreign goods. The "macro" elasticity between home and imported goods is in general smaller than the "micro" elasticity between foreign sources of imports. In a recent paper, Feenstra, Obstfeld and Russ (2012), find that the median micro elasticity is 3.1, while the macro elasticity between home and imported goods is close to one. We take a value in this range and choose $\eta=1.5$, closer to the macro estimates. Corrado, Hulten and Sichel (2009) report an average growth of labour productivity of 1.17 percent a year in the period 1970-79. Since steady state growth is $g=n /\left(1-\phi_{1}\right)$, using this value for productivity growth and the population growth rate we can back out $\phi_{1}=0.0256$. We set $\rho$, which in steady state is equal to the interest rate $r$, to 0.03 to match the risk-free rate on treasury bills. Finally, we calibrate the iceberg trade cost parameter $\tau$ using recent estimates from Novy (2013), who derive a micro-founded measure of bilateral trade costs indirectly inferring trade frictions from observable trade data. The average tariff-equivalent US bilateral trade costs with its major

${ }^{21}$ Agents choose whether to go to college at the age of 18 , so that the 18 year old cohort in 1979 is represented by people born in 1961, and life expectancy at birth in 1961 in the US is 70 years. We also include retirement years into working life, by assuming that pensions are proportional (equal for simplicity) to wages during working life. 
Review of Economics and Statistics Just Accepted MS.

doi:10.1162/REST_a_00551

(C) by the President and Fellows of Harvard College and the Massachusetts Institute of Technology

trading partners is found to be $74 \%$ in 1970 , which corresponds to setting $\tau=1.74$ in our model 22 We normalize $A^{F}$ and $z^{F}$ to one without loss of generality.

We simultaneously choose the remaining parameters,

$$
\chi \equiv\left[\epsilon, \varphi, \beta, \varepsilon, A^{D}, z^{D}\right] \in \Xi
$$

so that the numerical steady-state solution of the model matches relevant statistics. The parameters are calibrated in order to minimize a loss function defined by the quadratic distance between the moments in the model and the targeted statistics. Technology parameters $\beta, \varphi$ and $z^{D}$ pin down the factor intensity of our economy and contribute to determining the relative wages $\tilde{w}_{H}^{D} / \tilde{w}_{L}^{D}$ and $\tilde{w}_{S}^{D} / \tilde{w}_{L}^{D}$. Hence we target the relative wages reported in our Table 2 from Autor and Dorn (2013). The 1980 value of ratio of the average skilled wage to average unskilled wage excluding services (1.276), the unskilled/service workers wage ratio (1.62), and the more standard skill premium, the average wage of skilled workers divided by the average wage of all unskilled workers, production plus service sector workers. The 1980 value obtained from Autor and Dorn (2013) data is 1.37. Moreover, parameters $\epsilon, \varepsilon$, together with $\beta$ and $\varphi$, are key in determining the occupational structure: the share of the workforce acquiring skills, the share of unskilled workers employed in production and the share of those employed in service activities. We use Autor and Dorn (2013) data targeting a share of skilled workers of 31\% and a share of unskilled of $58 \% .23$ The innovation productivity parameter $A^{D}$ is influential in determining the geographical distribution of patents, hence we target the average 1977-80 share of US patents in the US patent office (64\%) shown in the motivation section ${ }^{24}$ Finally, we target the 1980

${ }^{22}$ The US major trading partners included in the estimation are, Germany, Japan, UK, Canada, Korea, and Mexico. The average US bilateral trade cost is obtained using bilateral trade volumes as weights.

${ }^{23}$ The share of service sectors workers can be obtained as a residual once these other two shares are computed.

${ }^{24}$ Notice that the sectorial production function for innnovation corresponding to cost functions $F^{D}$ and $F^{F}$ is $I^{K}=A^{K} \Omega\left(L^{K}\right)^{\varphi}\left(H^{K}\right)^{1-\varphi} / X$, where $\Omega=\varphi^{\varphi}(1-\varphi)^{1-\varphi}$. The value of 
wealth-to-income ratio. The statistic consistent with our theoretical model is the Corporate Equity/National Income ratio in Piketty and Zucman (2014) shown in Figure 2.

The calibration method is the following: define $\mathbf{m}=\left[m_{1}, \ldots, m_{8}\right]$ as the vector of the real data moments described above, and $y(\chi)$ the vector of equilibrium model moments generated by some vector of parameters $\chi$. Our calibrated parameter vector is obtained solving numerically

$$
\hat{\chi}=\underset{\chi \in \Xi}{\arg \min }\left[(y(\chi)-\mathbf{m}) \cdot W \cdot(y(\chi)-\mathbf{m})^{\prime}\right]
$$

where $W$ is the weighting matrix. We use a diagonal matrix with the squares of the data targets on the diagonal and zero for all other entries; formally $W_{i i}=1 / m_{i}^{2}$. The set of possible parameter values $\Xi$ contains the minimal restrictions of non-negativity and the bound between 0 and 1 for parameters $\epsilon, \varphi$, and $\beta$.

the total factor productivity in innovation $A^{K}$ is then key in determining innovation output, which in the data we can proxy with patent counts. Hence, the US patent share, represented by $I^{D} / I^{F}$ in the model is a good target for the technology gap $A^{F} / A^{D}$. 
Review of Economics and Statistics Just Accepted MS.

doi:10.1162/REST_a_00551

(C) by the President and Fellows of Harvard College and the Massachusetts Institute of Technology

\section{Table 3: Calibration and model fit}

\begin{tabular}{lcll}
\hline \hline \multicolumn{4}{c}{ Parameters taken from external sources } \\
Parameters & Value & Interpretation & Source \\
\hline$\eta$ & 1.5 & Elasticity of substitution & Feenstra et al., 2012 \\
$\lambda$ & 1.3 & Markup & Basu, 1996 \\
$\rho$ & 0.03 & Annual interest rate & Standard \\
$n$ & 1.14 & Population growth & BLS, 1999 \\
$\tau$ & 1.74 & Variable trade cost & Novy, 2013 \\
$V$ & 52 & Life expectancy after college & National Vital Statistics, 2010 \\
$T_{H}$ & 4 & Average years of college & Standard \\
\hline \hline
\end{tabular}

Calibrated parameters and model fit

\begin{tabular}{lllcc} 
Parameters & Value & Moment & Data & Model \\
\hline Innov. difficulty, $\phi_{1}$ & 0.025 & Productivity growth & 1.17 & 1.17 \\
Service efficiency, $\epsilon$ & 0.433 & Skill/unskilled wage & 1.28 & 1.40 \\
Ability curvature, $\varepsilon$ & 6.582 & Skill premium & 1.37 & 1.47 \\
Production technology, $z^{D}$ & 1.512 & Unskilled/service wage & 1.62 & 1.40 \\
Factor intensity: production, $\beta$ & 0.512 & Skilled workers \% & 31.5 & 30.0 \\
Factor intensity: innovation, $\varphi$ & 0.023 & Service workers $\%$ & 9.90 & 9.70 \\
Technology gap: $A^{F} / A^{D}$ & 0.196 & Unskilled workers \% & 58.5 & 57.0 \\
& & US patent share \% & 63.0 & 63.0 \\
& & Wealth to income ratio & 0.67 & 0.67 \\
\hline \hline
\end{tabular}


Review of Economics and Statistics Just Accepted MS.

doi:10.1162/REST_a_00551

(C) by the President and Fellows of Harvard College and the Massachusetts Institute of Technology

This procedure leads to the calibrated values listed in Table 3, which also reports the fit of the calibrated model. We use unskilled workers (and wages) to indicate the non-educated workers employed outside personal service occupations (production and innovation), while service workers (and wages) refer to unskilled workers employed in services. The model captures fairly well most features of the data, providing a good fit of the targets.

Globalization and wage polarization. Here we show the effects of globalization, in the form of increasing foreign technological competition, on the wage and occupational structure. In Figure 4, we report the effects of an increase in foreign innovation productivity $A^{F}$ keeping $A^{D}$ constant. More precisely, this exercise shows how the steady state of the model changes as $A^{F}$ converges to $A^{D}$.

The key analytical results of the baseline model seem to be confirmed in the numerical simulation: the shares of skilled and service sector workers increase while the share of unskilled workers (excluding services) decreases. Inequality at the top of the ability distribution, the skilled/unskilled relative wage, increases while inequality at the bottom, the unskilled/service wage ratio, decreases. Hence, the reduction in the technology gap reproduces qualitatively the polarization of US wages and occupations documented by Autor and Dorn (2013). The economic mechanisms connecting the technology gap and the wage structure are, as in the baseline model, the business stealing and the global competition effect. The former can be observed in the reduction in the US patent share, which in the model is represented by the share of sectors with domestic leadership $q^{D}$. The global competition effect can be seen in the sharp increase in the innovation difficulty index $x$. Finally, notice that since in this generalized model, as in the baseline model, only foreign firms can limit-price country $D$ firms, changes in the technology gap do not affect country $F$ polarization. As discussed in Section 5 , the business stealing effect cannot affect the wage and the skill structure in country $F$, as it does not have an impact on firms' markup. The global competition effect is not operative either since the potentially higher demand for skills triggered by the increase in innovation difficulty is offset by the improvement in the relative innovation efficiency. 
Review of Economics and Statistics Just Accepted MS.

doi:10.1162/REST_a_00551

(C) by the President and Fellows of Harvard College and the Massachusetts Institute of Technology

Figure 4: Technology Gap and Labour Market Polarisation

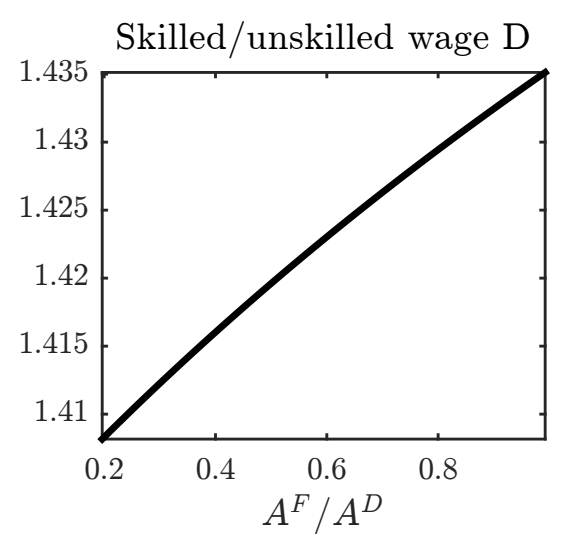

Patent Share D

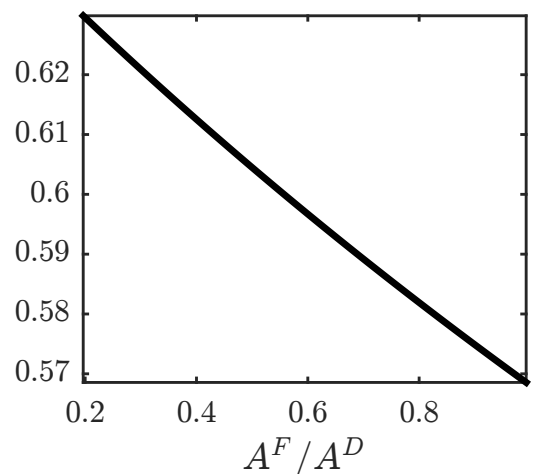

Service Workers D

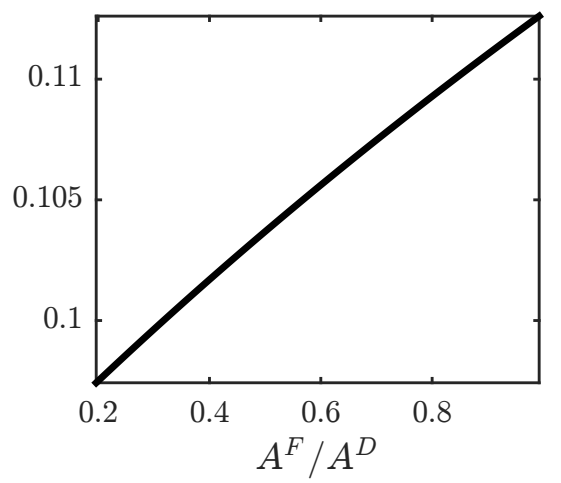

Skilled/unskilled wage $\mathrm{F}$

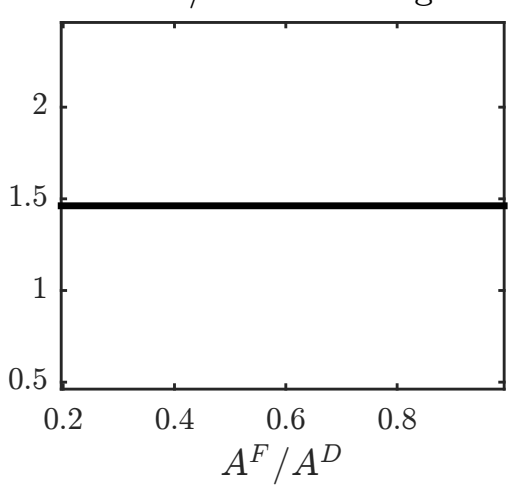

Skill Premium D

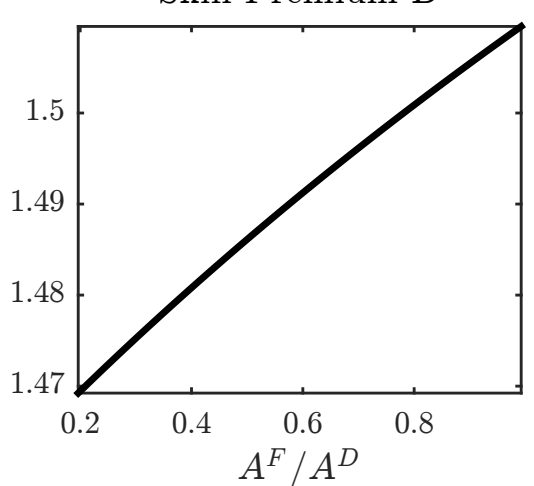

Skilled Workers D

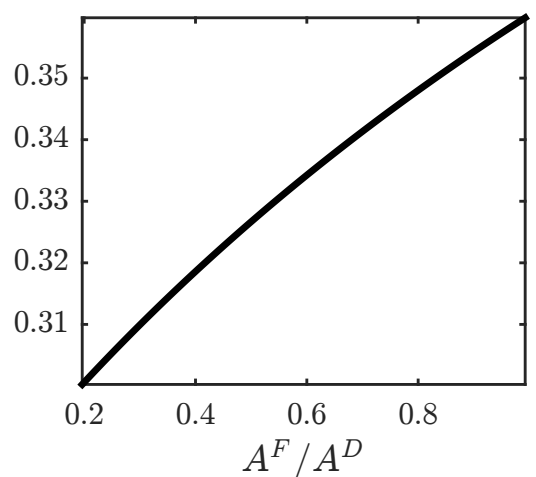

Innovation Difficulty $\mathrm{x}$

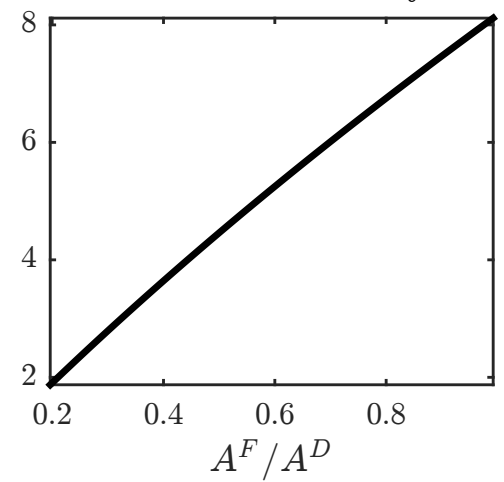

Skill Premium F

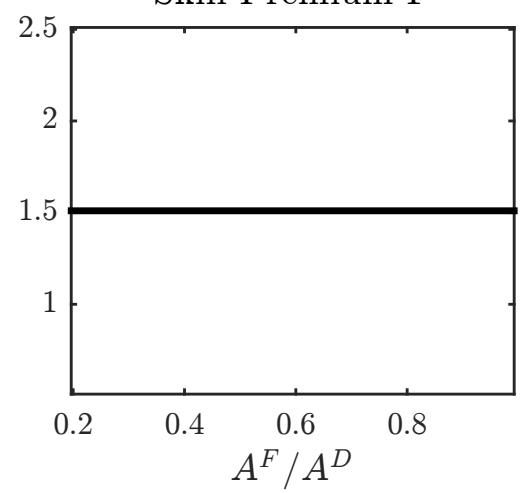

Unskilled/Service Wage D

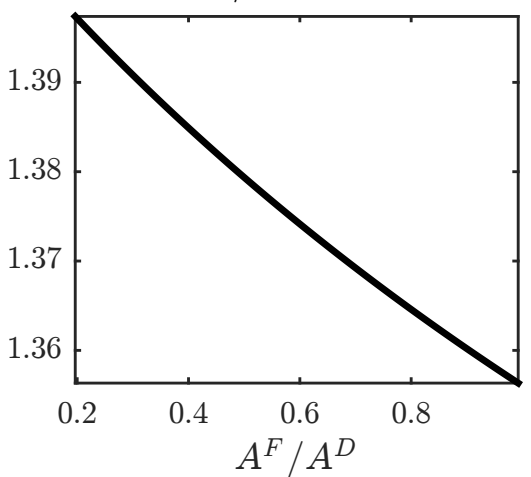

Unskilled Workers D

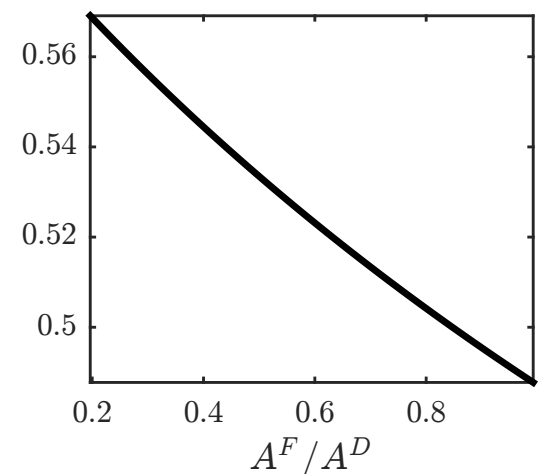

Wealth-Income Ratio

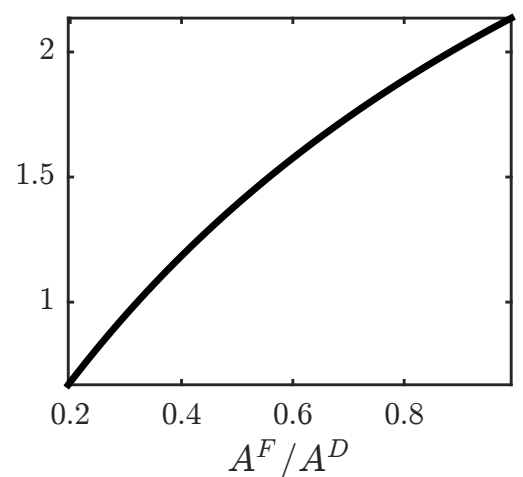

Unskilled/Service wage $\mathrm{F}$

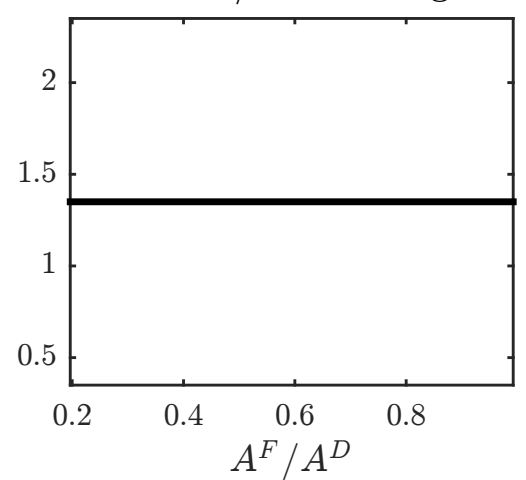


Review of Economics and Statistics Just Accepted MS.

doi:10.1162/REST_a_00551

(C) by the President and Fellows of Harvard College and the Massachusetts Institute of Technology

Table 4 shows that convergence in innovation technology reproduces about $62 \%$ of the reduction in the US patent share observed in the data, along with about $10 \%$ of the increase in wage inequality at the upper tails of the skill distribution (the skilled-unskilled wage ratio), about $18 \%$ of the decrease in inequality at the bottom of the skill distribution (unskilled/service ratio), and $16 \%$ of the increase in the skill premium documented by Autor and Dorn (2013). These results suggest that globalization, in the form of fiercer foreign technological competition, can be an important source of wage polarization. Certainly, other channels such as routine tasks-replacing technical change and other dimensions of globalization have contributed to the recent evolution of labour market polarization. Our mechanism provides a new channel that complements existing explanations of these important facts. Finally, our model allows us to replicate a sizable share of the evolution of the wealth-income ratio documented by Piketty and Zucman (2014). 
Review of Economics and Statistics Just Accepted MS.

doi:10.1162/REST_a_00551

(C) by the President and Fellows of Harvard College and the Massachusetts Institute of Technology

Table 4: Quantitative Results

\begin{tabular}{lcccc}
\hline \hline Moments & Data & Model & Data & Model \\
& $(1980)$ & $(1980)$ & $(2000)$ & $(2000)$ \\
\hline US Patent share & 63.0 & 63.0 & 53.0 & 56.8 \\
Skill/Unskilled Wage & 1.28 & 1.40 & 1.49 & 1.43 \\
Skill Premium & 1.37 & 1.47 & 1.61 & 1.51 \\
Unskilled/Service Wage & 1.62 & 1.39 & 1.46 & 1.36 \\
Skilled Workers \% & 31.5 & 30.0 & 39.6 & 36.0 \\
Unskilled Workers \% & 58.5 & 56.9 & 48.7 & 48.7 \\
Service Workers \% & 9.90 & 9.70 & 11.5 & 11.2 \\
Wealth to income ratio & 0.67 & 0.67 & 2.82 & 2.13 \\
\hline \hline
\end{tabular}


Although the scope of the paper is not to explain the dynamics of inequality in the foreign region, it is worth highlighting that the model's predictions are consistent with the evidence on inequality in several advanced countries that were catching up with the US during our period of analysis. In the literature, there is substantial evidence that the skill premium and other key measures of wage inequality are mostly stable or slightly decreasing in these countries. FuchsSchundeln, Krueger, and Sommer (2010) find a stable education premium and a stable residual wage variance in Germany between 1982 and 1995. Similar results can be found in Pijoan-Mas and Sanchez-Marcos (2010) for Spain, but the data are limited to the 1990s. Domenej and Floden (2010) report declines of both measures of inequality for Sweden in the period 1975-95. Kambayashi et al. (2008) and Lise, Sudo, Suzuki, Yamada and Yamada (2014) show that the education premium and residual wage inequality in Japan are stable or slightly declining in our period of analysis. Jappelli and Pistaferri (2010) find a stable education premium in Italy. Hence the stability of inequality in these countries is fairly well captured by our model.

For completeness, in the online appendix we show that if we move away from our benchmark calibration and consider the case $Z^{D}\left(w_{L}^{D}, w_{H}^{D}\right)<\tau$, the model can generate a reduction in all measures of inequality in country $F$, in response to decreases in the technology gap. As explained above, when trade cost are large both countries unit costs can potentially represent the competitive fringe that pins down equilibrium limit pricing. Hence, the business-stealing effect becomes operative in country $F$ as well, but works in the opposite direction compared to country $D$. Foreign business stealing reduces production costs in country $D$, thereby increasing firm profits and the incentives to innovate. Conversely, as country F's firms steal country D's market shares, foreign production wages and unit costs increase, thus leading to lower profits and lower innovation incentives. It follows that the effects of a reduction in the technology gap on the demand for skills and on wage polarization is opposite for the two countries.

\section{Conclusion}

Technological catch-up with the US has been a salient feature of the post-WWII global economy. Several countries have increased their ability to compete with the US and successfully entered 
Review of Economics and Statistics Just Accepted MS.

doi:10.1162/REST_a_00551

(C) by the President and Fellows of Harvard College and the Massachusetts Institute of Technology

innovation races for global market leadership: France, Germany, Japan, and South Korea earlier, and more recently China. This catching-up process is in part reflected in a particular dimension of globalization we zero in on, where lagging countries enter global innovation races and effectively compete with technological leaders.

Our analysis shows that such process of technological globalization can be an important source of wage inequality. Fiercer foreign technological competition determines an erosion of US industrial base, depressing unskilled wages and raising the remuneration of skilled workers. More innovation in the rest of the world also raises the difficulty of innovation and, consequently, more resources must be devoted to it in order to compete in the global playing field. Thus the demand for high skilled workers, used more intensively in innovation, increases together with their remuneration. As skilled labour time becomes more valuable, personal services that free labour time are more in demand, thus generating an upward pressure on wages and employment levels. Hence, globalization leads to wage polarization, to the advantage of the upper and lower tails of the skill distribution and to the detriment of occupations performed by workers with intermediate levels of skills. When matched to US data, our model reproduces a non-negligible part of the increase in US wage polarization in the 1980-2000 period.

An additional prediction of our model is that more intense foreign technological competition increases the wealth-income ratio, in line with recent evidence. Globalization increases corporate profits and the market value of leading firms by reducing labour costs and increasing the competition for global market leadership. Since wealth is the aggregate stock market value of firms, globalization leads to higher wealth-income ratio along with faster technical change and growth. Hence, our Schumpeterian framework suggests that innovation and growth, rather than economic stagnation, are the ultimate sources of inequality 25

\section{References}

[1] Acemoglu, D., "Patterns of Skill Premia," Review of Economic Studies, 70 (2003), 199-230.

\footnotetext{
${ }^{25}$ For an different view see Piketty (2014) and Piketty and Zucman (2014).
} 
[2] Acemoglu, D., and D. Autor, "Skills, Tasks and Technologies:Implications for Employment and Earnings," (pp.1043-1171) in O. Ashenfelter and D. E. Card (eds.), Handbook of Labor Economics (Amsterdam: Elsevier, 2011).

[3] Aghion P., and P. Howitt, "A Model of Growth through Creative Destruction," Econometrica 60:2 (1992), 323-351.

[4] Akcigit, U., S. Ates, G. Impullitti, "Technology Dynamics, Innovation Policy and the Gains from Globalization," University of Pennsylvania mimeograph (2014).

[5] Autor D. and D. Dorn, "The Growth of Low-Skill Service Jobs and the Polarization of the US Labor Market,", American Economic Review, 103:5 (2013), 1553-1597.

[6] Basu, S., "Procyclical Productivity: Increasing Returns or Cyclical Utilization?," Quarterly Journal of Economics, 111 (1996), 709-751.

[7] Blundell, R., R. Griffith, and F. Windmeijer, "Individual Effects and Dynamics in Count Data Models", Journal of Econometrics 180 (2002), 113-131.

[8] Burstein, A., and J. Vogel, "International Trade, Technology, and the Skill Premium," UCLA mimeograph (2012).

[9] Corrado, C., C. Hulten, and D. Sichel, (2009). "Intangible Capital And U.S. Economic Growth," Review of Income and Wealth, 55:3 661-685.

[10] Cozzi, G., (2007). "The Arrow effect under competitive R\&D," The B.E. Journal of Macroeconomics (Contributions), 7, Article 2.

[11] Dinopoulos E. and P. Segerstrom, "A Schumpeterian Model of Protection and Relative Wages," American Economic Review 89 (1999), 450-472.

[12] Domeij, D. and M. Floden, "Inequality Trends in Sweden 1978-2004," Review of Economic Dynamics, 13 (2010), 179-208. 
[13] Eaton, J., and S. Kortum, "Innovation, Diffusion, and Trade," (pp. 276-299) in E. Sheshinski, R. J. Strom, and W. J. Baumol (eds.), Entrepreneurship, Innovation, and the Growth Mechanism of the Free-Enterprise Economies (Princeton NJ: Princeton University Press, 2007).

[14] Epifani, P., and G. Gancia, "The Skill Bias of World Trade", The Economic Journal, 118 (2008), 927-960.

[15] Feenstra, R., M. Obstfeld, and K. Russ, "In Search of the Armington Elasticity", UCSD mimeograph (2012).

[16] Glass, A.J., "Product Cycles and Market Penetration," International Economic Review, 38 (1997), 865-891.

[17] Grossman G. M. and E. Helpman, Innovation and Growth in the Global Economy (Cambridge MA: MIT Press, 1991).

[18] Hall, B., Griliches, Z., and J, Hausman, "Patents and R\&D: is there a Lag?," International Economic Review, 27 (1986), 265-83.

[19] Hemous, D., and M. Olsen, "The Rise of the Machines: Automation, Horizontal Innovation and Income Inequality," INSEAD mimeograph (2014).

[20] Hsieh, C.T., and R. Ossa, "A Global View of Productivity Growth in China," NBER Working Paper 16778 (2011).

[21] Impullitti, G., "International Competition and US R\&D Subsidies: a Quantitative Welfare Analysis," International Economic Review, 51:4 (2010), 1127-1158.

[22] Impullitti, G., "Global Innovation Races, Offshoring and Wage Inequality," University of Nottingham, mimeograph (2015).

[23] Jappelli, T., and L. Pistaferri, "Does Consumption Inequality Track Income Inequality in Italy?," Review of Economic Dynamics, 13 (2010), 133-153. 
Review of Economics and Statistics Just Accepted MS.

doi:10.1162/REST_a_00551

(C) by the President and Fellows of Harvard College and the Massachusetts Institute of Technology

[24] Jones C., "Time Series Tests of Endogenous Growth Models," Quarterly Journal of Economics 110 (1995), 495-525.

[25] Kambayashi, R., D. Kawaguchi, and I. Yokoyama, "Wage Distribution in Japan: 19892003," Canadian Journal of Economics, 41:4 (2008), 1329-1350.

[26] Kortum, S., "Equilibrium R\&D Ratio and the Patent-R\&D Ratio: US Evidence," American Economic Review P\&P 83 (1993), 450-457.

[27] Lise, J., N. Sudo, Suzuki, M., Yamada, K., Yamada, T., "Wage, Income and Consumption Inequality in Japan, 1981-2008," Review of Economic Dynamics, 17 (2014), 582-612.

[28] National Vital Statistics Reports, 58:21, June (2010).

[29] Novy, D. (2013). "Gravity Redux: Measuring International Trade Costs with Panel Data" Economic Inquiry, 51:1 (2013), 101-121.

[30] Mazzolari, E. and G. Ragusa, "Spillovers from High- Skill Consumption to Low-Skill Labor Markets," this Review, 95:1 (2013), 74-86.

[31] Pijoan-Mas J., and V. Sanchez-Marcos, "Spain is Different: Falling Trends in Inequality," Review of Economic Dynamics, 13:1 (2010), 157-178.

[32] Piketty, T., Capital in the Twenty-first Century (Cambridge MA: Harvard University Press, 2014).

[33] Piketty, T. and G. Zucman, "Capital is Back: Wealth-Income Ratios in Rich Countries, 1700-2010," Quarterly Journal of Economics, 129:3 (2014), 1255-1310. 